\title{
IDENTIFICATION OF SLAM EVENTS EXPERIENCED BY A HIGH- SPEED CRAFT
}

\section{NOMENCLATURE}

$\begin{array}{ll}\text { a, m } & \text { Fatigue curve parameters } \\ \text { ACPB } & \text { Armidale Class Patrol Boat } \\ \text { CL } & \text { Centreline } \\ \text { D } & \text { Fatigue damage } \\ \text { DSTG } & \text { Defence Science and Technology Group } \\ \mathrm{F}_{\mathrm{c}} & \text { Cut-off frequency }[\mathrm{Hz}] \\ \mathrm{F}_{\mathrm{e}} & \text { Average encounter wave frequency }[\mathrm{Hz}] \\ \mathrm{F}_{\mathrm{s}} & \text { Sampling rate }[\mathrm{Hz}] \\ \mathrm{F}_{\text {valley }} & \text { Frequency of valley between the first two peaks in a spectral response }[\mathrm{Hz}] \\ \mathrm{FP} & \text { Forward Perpendicular } \\ \mathrm{GPS} & \text { Global Positioning System } \\ \mathrm{HMAS} & \text { Her Majesty's Australian Ship } \\ \mathrm{HMS} & \text { Hull Monitoring System } \\ \mathrm{Hz} & \text { Hertz, cycles per second } \\ \mathrm{n} & \text { Number of stress cycles } \\ \mathrm{N} & \text { Number of stress cycles to failure } \\ \text { RAN } & \text { Royal Australian Navy } \\ \mathrm{RMS} & \text { Root Mean Square } \\ \Delta \sigma & \text { Stress range [MPa] } \\ \beta & \text { Multiplication factor } \\ \sigma / \sigma_{\text {allow }} & \text { Stress non-dimensionalised by allowable stress }\end{array}$

\section{INTRODUCTION}

Fatigue damage of a structural item occurs when exposed to numerous cycles of stress peaks (tensile) and troughs (compressive). The fatigue damage accumulates until the load-bearing capacity of the structural item falls below the applied load. Sources of cyclic loads experienced by a ship structure include wave action, inertial reactions from contents, hydrodynamic loads from appendages and propulsive devices, rotating machinery, and transient vibration induced by impact loads such as slamming (Hughes and Paik, 2010).

A slam event occurs when a vessel experiences sufficiently large heave and pitch motions such that the bow emerges from the water and re-enters with a heavy impact or slam. Slam loading is characterised by a rapid increase during water re-entry followed by high frequency transient vibration in the structure, or whipping, which decays rapidly (Dessi and Ciappi, 2013; Mansour and Liu, 2008).

The slamming loads and associated response of high-speed craft have been known to have a significant impact on the stress magnitudes experienced by the structure (Thomas et al., 2006; Thomas et al., 2003). Slamming may have a considerable influence on the fatigue life of highspeed craft when compared to accounting for the global wave induced stresses alone (Thomas et al., 2003; Zhu and Collette, 2011). In full-scale measurements of ships, stress components varying with the two-node hull girder vibration frequency have been observed. In general, these higher frequency stress amplitudes are much smaller than those seen in the direct wave- 
induced frequency range and therefore are usually not explicitly accounted for in the structural design of ships (Nielsen et al., 2011; Thomas et al., 2003).

Owing to operational requirements such as fast transport of troops and equipment and improved interception and apprehension capability, high-speed craft are being increasingly used in naval applications. In Australia, the Royal Australian Navy (RAN) operates a fleet of thirteen Armidale Class Patrol Boats (ACPBs). These vessels have a deep "V", hard-chine, semi-planing hullform, are constructed from marine-grade aluminium alloys, and operate in a tropical environment. The operational requirements of naval vessels are often demanding (Gudze et al., 2006; Kramer et al., 2006), and the loads applied to high-speed craft can feature a high degree of non-linearity. Knowledge of the structural behaviour of relatively high-speed craft supports informed decision-making in regards to the sustainability and maintainability of the current fleet and future acquisitions.

In order to improve an understanding of the influence of slamming on the fatigue life of highspeed craft, the definition of a slam event needs to be established. Treating slamming- and wave-induced stress components separately can also be practical in structural integrity assessments performed analytically or numerically. Similarly, the contributions of waveinduced and whipping stresses to the total stress can be related in a probabilistic manner. The peak values of the wave- and slamming-induced (whipping) loads may be asynchronous; the relationship between wave and slamming effects is dependent on the sea state, vessel speed, and wave frequency (Ćorak et al., 2013; Mansour and Liu, 2008). Therefore, slam event identification can be used to establish both the requirement and a practical approach to account for slamming loads in ship structural assessment based on a fatigue criterion.

Slam detection is also useful information in structural health monitoring and operational guidance. This can take the form of a slam avoidance system that predicts the possibility of a vessel approaching operating conditions that could induce slamming. Alternatively, a slam monitor can also indicate the trend over time in relation to impacts that exceeds warning levels. Colwell and Stredulinksy (2008) discussed the development of polar plots to indicate which combinations of vessel speed and heading can lead to a high probability of exceedance levels for slamming loads on the KINGSTON Class Maritime Coastal Defence Vessel. The authors also examined ways to provide real time operator guidance to enable informed evaluation of the risk of severe slamming versus the urgency of the mission. Part of this work was selection of an appropriate parameter to indicate slam severity, such as centreline vertical bow acceleration or structural response provided by strain gauges. Even so, efforts to improve operational advice regarding slamming and its effects on the structure have tended to be focused on larger vessels. Barhoumi and Storhaug (2013) presented an assessment of whipping and springing of a large container vessel. Data from an installed hull monitoring system was used to study fatigue damage rates with respect to re-routing and speed reduction and the associated whipping contribution. Nielsen et al. (2011) outlined a procedure for hullgirder fatigue damage rate prediction, taking into account whipping stresses, for hypothetical changes in ship course and speed. The proposed spectral method was verified against fullscale results of a container ship analysed by the rainflow counting method.

As driven by the need to improve fatigue life prediction of relatively high-speed craft, this paper presents an investigation of different approaches to characterise and count slam events using full-scale measurement data from an ACPB. Attention is directed to determining a robust method to decompose stress time records into its wave and whipping stress parts, indicative fatigue damage induced by slamming, and slam event definition and detection. Finally, areas of further work are discussed. 


\section{HULL MONITORING SYSTEM}

The Defence Science and Technology (DST) Group is conducting research aimed at improving understanding of the structural integrity of welded aluminium high-speed craft. Critical to this research is gathering data on the operational profile and the response to global and localised loading of a vessel in service. As such DST Group collaborated with Austal Ships to install and commission a Hull Monitoring System (HMS) onboard an ACPB, HMAS GLENELG. The aims of the project were to develop a capability for structural fleet management and Life-of-Type assessment, and to demonstrate the application of a versatile network using specialised sensors on a naval platform (Gardiner et al., 2008).

The HMS was comprised of accelerometers, strain gauges, torsion meters to measure shaft power, a six degree of freedom rigid body motion reference unit, and a Global Positioning System (GPS) (Vincent et al., 2008). The sensors were programmed to continuously collect and return data to the collection computer for storage at the following sampling rates, $F_{\mathrm{s}}$ of; 20 or $50 \mathrm{~Hz}$ for strain gauges and accelerometers, $20 \mathrm{~Hz}$ for the motion reference unit, $0.25 \mathrm{~Hz}$ for the GPS, and $0.24 \mathrm{~Hz}$ for the torsion meters. The HMS was operational from May 2009 until February 2014.

In the original arrangement of the system, strain gauges were located for the purpose of measuring both global and local strains. Global stresses were to be measured using strain gauges at three longitudinal sections; forward, towards midships, and aft. To detect strain events due to slamming, strain rosettes were located on the keel and several metres up from the keel. In general, locations that were predicated to be relatively highly stressed, and with a relatively uniform stress distribution, were instrumented (Gardiner et al., 2008). In 2012 additional strain gauges at various locations in the engine room were installed, in order to better understand the stresses induced in pillars and their supporting structure.

In order to support the sustainment of the ACPBs, knowledge of the effect of slamming over the whole range of environmental and operational conditions is required. Analysis of data acquired from the HMS has allowed a reliable operational profile of the ACPB fleet to be developed. HMAS GLENELG is considered to be representative of the class. Each ACPB was built over a period of three years in Austal Ships' Henderson shipyard, out of the same material and to effectively the same design. HMAS GLENELG is the last of class, and it would be expected that any structural changes and modifications introduced during the build period were included on the vessel. In addition, HMAS GLENELG is based in Darwin with the majority of the ACPBs.

The ACPBs' primary operational area is the North-West of Australia. Sea state information relating to this area has been sourced through the RAN Meteorology and Oceanography Office. From significant wave height statistics over a 2.5 year period, it has been deduced that HMAS GLENELG conducted its operations $86 \%$ of the time in seas up to the top of Sea State 4 , and $13 \%$ of the time in Sea State 5. HMAS GLENELG's speed profile features two speed ranges in which the vessel operates over $25 \%$ of the time; 4 to 6 knots, and 13 to 17 knots. The top speed is 25 knots (Aksu et al., 2015).

In this paper five strain gauge locations, displayed in Figure 1 and described in Table 1, are analysed. Strain gauges A, B, C were part of the original installation, and D and E were installed in 2012. Three sets of five consecutive hours in which HMAS GLENELG experienced relatively high stresses due to operating in significant sea states have been 
extracted. This data is used for the slam detection investigation. From satellite hindcast data of the significant wave heights covering the area of operations, the vessel encountered Sea State 5 during Sets 1 and 2, and Sea State 4 during Set 3. The stress measured by strain gauge A, vessel heading, and speed during each dataset are shown in Figure 2.

Figure 1 Profile view of ACPB showing strain gauge locations

Table 1 Description of strain gauge locations

Figure 2 Stress measured by strain gauge A, heading, and, vessel speed during Set 1, Set 2, and Set 3

During most of the duration of Set 1 the vessel was heading West at approximately 14 knots, though changed heading to East and dropped speed for a portion of the fourth hour. During most of the duration of Set 2, the vessel was heading South-South-West at approximately 16 knots. However, for parts of the second and third hours the vessel changed direction to East and dropped speed. Noticeable in both of these sets, at strain gauge location A the changes in the encounter wave frequency and speed reduction resulted in a substantial decrease in stress magnitudes. Also, the vessel speed features some variability which is attributed to involuntary speed reduction caused by the relatively severe sea state. During most of the duration of Set 3 the vessel was heading East at approximately 15 knots.

\section{DECOMPOSITION OF WAVE AND WHIPPING STRESS FROM TOTAL RESPONSE}

As previously mentioned, the decomposition of the slamming and wave-induced contributions from the total measured stress is important for the calibration of numerical models, and to gain a better understanding of the contribution of the individual stress components to fatigue (Carrera and Rizzo, 2005; Kwon et al., 2012; Nielsen et al., 2011). The structural response of a slamming load usually occurs at a higher frequency than the wave-induced response. To decompose the stress time record into its wave- and slam-induced constituents, the cut-off frequency which differentiates the low and high frequency signals is required to be found.

Spectral density estimates of the stress records are used to identify the cut-off frequency. A spectral density function of a time record provides a measure of the strength of its component frequencies. The ensemble-averaged spectral density estimates of the digitised stress record are computed using finite Fourier transforms, and a Hamming window is applied to the data to reduce spectral leakage.

As an example, Figure 3 shows the spectral density estimate of a one-hour time record at strain gauge location $\mathrm{A}$. The largest response of the structure is to wave-induced loading between 0 and $1.8 \mathrm{~Hz}$. The next two peaks in the response at approximately 2.5 and $5 \mathrm{~Hz}$ are the twonode and three-node natural modes of the ACPB structure. At approximately $13.58 \mathrm{~Hz}$ there is a sharp peak which is believed to be due to machinery vibrating in the vicinity of the strain gauge.

Figure 3 Spectral density estimation of a one hour time record at strain gauge location A

The spectral density estimates of each hour of response data in Set 1 , up to $10 \mathrm{~Hz}$, at strain gauge locations A, B and C are compared in Figure 4. As expected the frequencies at which peaks occur are similar.

Figure 4 Comparison of spectral density estimation of a one hour time record at all strain gauge locations 
The observations from the spectral density estimations of the measured strain records are verified by comparison to the results of natural frequency analysis of a finite element model of the ACPB. The natural frequency analysis was performed in MAESTRO 11.0.0 (2013). A displacement likely to be the operational condition of the ACPB was assumed, and stillwater conditions were used. In MAESTRO, fluid added mass is generated for all wettable elements (i.e. hull plating) below the waterline using a panel method. The mode extraction method selected was Subspace (DRS Defense Solutions, 2011).

The two-node and three-node mode shapes of the ACPB calculated using finite element analysis, in wet mode, are displayed in Figure 5 and Figure 6 respectively. A summary of the computed and measured two-node and three-node vibration frequencies is provided in Table 2. The values are comparable, and verify the natural frequencies found in the measured data. The small differences between the measured and computed frequencies are attributed to the numerical method used to calculate the mass of the seawater in the finite element software. In addition, as the vessel moves through waves it will heave and pitch the positions of the bending nodes move longitudinally.

\section{Figure 5 2-node mode shape of ACPB (scaled x1000)}

Figure 6 3-node mode shape of ACPB (scaled x1000)

\section{Table 2 Comparison of Computed and Measured Wet Mode Vibration Frequencies}

The sensitivity of the cut-off frequency $\mathrm{F}_{\mathrm{c}}$ on the resulting isolated wave-induced and whipping stresses is assessed to ensure that an appropriate value is used. For a high-speed catamaran, $F_{c}$ has been defined as the frequency where half the signal is attenuated, or double the average encounter wave frequency $F_{\mathrm{e}}$ (French, 2012). Alternatively, the cut-off between the wave frequency and the high frequency response has been represented by the valley between the first and second peaks in the power spectral density (Kwon et al., 2012; Nielsen et al., 2011; Thomas et al., 2003). As an indicator of the effect of $F_{c}$, Figure 7 shows the sensitivity of the Root Mean Square (RMS) of the difference between the total and waveinduced stresses (residual) to $F_{c}$ at strain gauge location A during sets 1 and 2. $F_{c}$ is expressed as $F_{e}$ multiplied by a factor $\beta$. For all hours the residual decreases as $F_{c}$ increases, though becomes asymptotical. A similar trend was reported in (French, 2012). In Figure 8 the sensitivity of the decomposition of the total stress to $F_{c}$ is illustrated in the time domain via samples of the total, wave-induced and whipping stress (non-dimensionalised by the allowable stress $\sigma_{\text {allow }}$ of the ACPB) for $\beta$ values of 2 and 11 . When $F_{c}$ is double $F_{e}$, though the residual is reduced by approximately $40 \%$ (see Figure 7), the underlying wave response does not match large rises and falls in the total response. On the other hand when $\beta$ is 11 , and almost coincides with frequency at which the valley between the first two peaks in the spectral response occurs $\mathrm{F}_{\text {valley, }}$, the residual is reduced by approximately $85 \%$ and the wave-induced stress time record better follows the behaviour of the total stress. Therefore, to ensure that the wave and whipping responses are appropriately isolated, $\mathrm{F}_{\mathrm{c}}$ for the ACPB is defined as $\mathrm{F}_{\text {valley. }}$

Figure 7 RMS of difference between total and wave-induced stress (residual) at strain gauge location A

Figure 8 Sensitivity of wave-induced and whipping stresses to $\beta=2$ and $11\left(F_{c}=\beta F_{e}\right)$

Based on the above results, the wave-induced and whipping stress components are obtained using steps outlined in (Kwon et al., 2012; Nielsen et al., 2011; Thomas et al., 2003). The structural response is assumed to be the measurement of strain below $7.5 \mathrm{~Hz}$; vibration modes 
greater than $7.5 \mathrm{~Hz}$ die out quickly because of strong structural damping characteristics. As such, the signal above $7.5 \mathrm{~Hz}$ is truncated by applying a Chebyshev low pass filter to produce the filtered "total" stress record. The cut-off between the wave frequency and the high frequency response is represented by the valley between the first and second peaks in the power spectral density. As evidenced in Figure $4 \mathrm{~F}_{\mathrm{c}}$ varies with the location due to proximity to a node or anti-node. Further, $F_{c}$ is influenced by wave heading, wave period and displacement of the vessel. As such, $F_{c}$ is determined for each hour of strain data for each gauge. The whipping component of the stress record is obtained by applying a Chebyshev band pass filter between the valley and $7.5 \mathrm{~Hz}$. The wave-induced component can also be determined by applying the Chebyshev band pass filter between 0 and $\mathrm{F}_{\mathrm{c}}$.

The location of $F_{c}$ is shown in the hourly spectral density estimates for Set 1 in Figure 4. The value of $F_{c}$ varies slightly per hour.

Figure 9 shows a sample of the total stress record, and its associated wave-induced and whipping components, at strain gauge locations $\mathrm{A}, \mathrm{B}$, and $\mathrm{C}$. This section of the time record is highlighted because at approximately $1900 \mathrm{~s}$ the vessel responded to a relatively severe slam impact. This is exhibited by a relatively large increase in the total stress. The impulsive loading of the slam imparted sufficient energy at the bottom forward section of the hull to excite transient vibration, as evidenced by the large oscillations in the slamming-induced stress component beginning at approximately $1900 \mathrm{~s}$ at strain gauge location $\mathrm{A}$. The whipping persisted for about three seconds before being damped so that only the underlying wave response remained. In contrast, there are fewer whipping oscillations visible at strain gauge location $\mathrm{C}$ than at the bottom gauges. One possible explanation for this is that the energy of the slam, propagating from the bottom forward section of the hull through the structure, is dampened by the hull-girder. This results in reduced frequency vibration further aft and on the superstructure.

Particularly perceptible at strain gauge location A, the magnitude of the peak and the trough of the wave-induced stress during the slam event at $1900 \mathrm{~s}$ were significantly large compared to those of the proceeding and subsequent wave encounters. That is, the contribution of the whipping stress alone does not account for the large stress rise and magnitude of the total stress in the slam event. When the vessel encounters a relatively large wave, the energy from the heavy slam impact is partly absorbed by the forward, bottom section of the hull. This manifests as a significant stress rise generally in the sagging condition, in addition to excitation of bending modes. As such, there is distinctive asymmetry in the stress response between the sagging and hogging conditions.

Figure 9 Sample stress record from Set 1 hour 1 at strain gauge location A, B, and C

The largest stress response occurred at strain gauge location A, being located on the centreline girder.

\section{IMPORTANCE OF SLAMMING}

Fatigue loading is the ensemble of different structural load variations of particular magnitude and occurring in a certain sequence. The loading of the structure depends on its modes of operation; for ships this is characterised by sea state and speed.

To demonstrate the importance of the high frequency hull-girder response in fatigue damage estimation of the ACPB, a counting procedure and cumulative damage theory are applied to the stress measurements. The stress records were reduced into spectra of cycles in terms of 
stress range $\Delta \sigma$ and number of cycles $n$ by use of the rainflow counting method (Rychlik, 1987). Using the Palmgren-Miner rule (Miner, 1945) the fatigue damage D caused by all cycles, where $\mathrm{k}$ is the number of stress ranges, and a and $\mathrm{m}$ are $\Delta \sigma-\mathrm{N}$ curve parameters (the basic $\Delta \sigma-\mathrm{N}$ curve form is $\left.\log (\mathrm{N})=\log (\mathrm{a})-\log \left(\Delta \sigma_{i}\right)\right)$ is calculated using Equation 1 .

\section{Equation 1}

$\mathrm{D}=\sum_{\mathrm{i}=1}^{\mathrm{k}} \frac{\mathrm{n}_{\mathrm{i}}}{\mathrm{N}_{\mathrm{i}}}=\frac{1}{\overline{\mathrm{a}}} \sum_{\mathrm{i}=1}^{\mathrm{k}} \mathrm{n}_{\mathrm{i}}\left(\Delta \sigma_{\mathrm{i}}\right)^{\mathrm{m}}$

Eurocode 9 construction details and fatigue resistance data (Technical Committee CEN/TC $250,1999)$ are available for use in fatigue analysis. Eurocode 9 is an aluminium structural design code specified by the European Committee for Standardization. The code provides $\mathrm{S}-\mathrm{N}$ $(\Delta \sigma-N)$ curves, which relate nominal applied cyclic stress ranges to the corresponding number of cycles needed to cause failure.

The construction detail selected for each strain gauge location is given in Table 3. It should be noted that there is some uncertainty in the selection of the construction detail of each strain gauge location. It has been observed that some structural details found on aluminium high speed light craft cannot be found in design codes, which may in part be due to the lack of information on the fatigue strength of typical structural details (Sielski, 2008). The sensitivity of the fatigue life estimation to the selection of the construction detail at some of strain gauge locations on HMAS GLENELG has been investigated by Aksu et al. (2015).

\section{Table 3 Detail categories of strain gauge locations}

To appreciate the contribution of the high frequency slamming response to fatigue damage in the ACPB structure, plots of the fatigue damage estimated using the total stress and waveinduced component of the stress time records for the five strain gauges considered are provided in Figure 10. Time records for strain gauges A and B were available for all sets. However, strain gauge $\mathrm{C}$ was damaged before the time covered in Set 3 and as such fatigue damage values are unavailable. Also, strain gauges $\mathrm{D}$ and $\mathrm{E}$ were installed at a later stage and thus the respective fatigue damage values are only available for Set 3.

To derive the fatigue damage accumulated due to slamming, it is assumed that the slaminduced component is the difference between the total fatigue damage and that derived from the wave-induced component. This definition has been used in estimations of the fatigue damage of a container ship based on full-scale measurements of hull girder stresses (Ito et al., 2010; Nielsen et al., 2011).

As indicated by the difference in the fatigue damage estimated using the total stress and waveinduced stress component from Figure 10, the contribution of slamming to the fatigue damage is generally considerable at all strain gauge locations. During Set 1 the average contribution of slamming to the fatigue damage at strain gauge location A was $46 \%$, at B $35 \%$, and at C $37 \%$. The slamming contribution during Set 2 was similar; $48 \%$ at strain gauge location A, $36 \%$ at B, and $35 \%$ at $\mathrm{C}$. For Set 3 the average contribution of slamming to the fatigue damage at strain gauge location A was 50\%, at B 40\%, at D $49 \%$, and at E 57\%.

Figure 10 Hourly fatigue damage incurred at different strain gauge locations, estimated using total and wave-induced stress time records 
During Sets 1 and 2, the largest fatigue damage occurred at strain gauge location A. However, during Set 3 the largest fatigue damage was incurred at strain gauge location E. It should be noted that stresses at these strain gauge locations do not necessarily represent the largest stresses observed in the structure, as the strain gauges were located in relatively easily accessible areas and away from major stress concentrations.

Figure 10 also illustrates that the period in which the vessel sustained the most fatigue damage was during Set 1.

\section{SLAM IDENTIFICATION}

Approaches to establish a ship-specific slam event definition by interpreting structural response data have been investigated. Ochi (1964) concluded that two conditions were necessary for slamming to occur; the relative motion must exceed the sectional draft, and the relative velocity at the instant of re-entry must exceed a threshold magnitude specific to a vessel. However, Dessi and Ciappi (2013) found that in segmented-hull model testing, slam events that did not satisfy the Ochi velocity threshold were responsible for large vertical bending moments. As such the authors proposed a slam event identification method labelled the whipping criterion, whereby the whipping response in the form of the high frequency contribution to the total vertical bending moment was set. Thomas et al. (2003) used a stress derivative threshold as a criterion for slamming detection. The definition is independent of strain gauge location and sea state conditions. Alternatively, the damage incurred in the structure due to slamming can be considered. Thomas et al. (2006) proposed a criterion based on fatigue damage. The stress level at which the fatigue resistance curve of a particular material and structural detail provides a criterion for defining a threshold above which slam events are significant.

Given that no universally accepted criterion for identification of slams exists in the open literature, a slam criterion for the ACPB based on the measurement data is investigated. The approaches considered are; application of a stress magnitude threshold, application of a stress rate threshold, and fatigue damage contribution of slam events.

Although Thomas et al. (2003) examined thresholds applied to the total stress to detect slam events experienced by a catamaran, for the present vessel assessment of thresholds based on the whipping stress is suitable. This is because the magnitude and/or the rate of the total stress can exceed the defined target without excitation of transient vibration. This is exemplified in Figure 11, which shows that six peaks were identified as slams under application of a total stress threshold at strain gauge location A. However, the second and sixth peaks are associated with relatively minor high frequency vibration and are thus not true slam events. Therefore, algorithms to detect slam events are applied to the isolated whipping stress.

Figure 11 Sample of slam detection using total stress rate threshold at strain gauge location A (peak of slam event depicted by cross) and whipping stress component

As discussed by Colwell and Stredulinsky (2008), the provision of effective operator guidance regarding slam severity is dependent on the selection of an appropriate indicator (i.e. location and type of sensor). Based on the sample stress time record shown in Figure 9, strain gauge C is not a good candidate for slam detection because the high frequency component of the stress does not feature the multiple oscillations and decay of typical slam events. However, a strain gauge located on the forward section of the centreline girder is an effective reference. As this part of the structure experiences the slam impact, and is on the centreline, addressing complexities such as structural damping and asymmetry in the response can be avoided. 
Therefore, strain gauges B and C are discounted in the remaining analysis and A is deemed the reference gauge.

\subsection{STRESS CRITERION}

Application of a stress magnitude threshold involves determining if the whipping stress within one slam event exceeds a defined target stress, for example a percentage of the allowable stress $\sigma_{\text {allow. }}$ The magnitude of the target stress was chosen by conducting a sensitivity analysis that gauged the effect that the variation of the percentage of $\sigma_{\text {allow }}$ had in the number of slams detected. Stress threshold values between $1.45 \%$ and $2.45 \%$ of $\sigma_{\text {allow }}$ in $0.25 \%$ increments were set in order to compute the number of slams at strain gauge location $\mathrm{A}$.

A sample total stress time record and the corresponding slam-induced component with detected slam events is provided in Figure 12. The stress peaks and troughs of the slams are denoted by crosses and asterisks.

For the timeframe shown in Figure 12, four slams were detected at strain gauge location A. Interestingly, though a relatively large peak in the total stress occurred at approximately 1913 $\mathrm{s}$ it was not counted as a slam event because the whipping response was below the threshold. A similar total stress peak at approximately $1916 \mathrm{~s}$ was identified as a slam event as the whipping response exceeded the defined threshold. The magnitude, temporal and spatial distributions of wave and slamming loads have different dependencies to the encountered wave height and frequency and vessel speed. Given the probabilistic nature of wave and slam loads, it can be expected that the whipping stress relative to the total stress can vary from one wave encounter to the next.

Figure 12 Sample of slam detection using stress magnitude threshold at strain gauge location A (peak and trough depicted by cross and asterisk)

\subsection{STRESS RATE CRITERION}

Application of a stress rate threshold involves determining if the derivative of the whipping stress within one slam event exceeds a defined target. This method is proposed to be favourable over the stress magnitude criterion, because the threshold values need to be modified as the sea conditions (sea state) change, and slowly changing stress peaks with large magnitude are identified but small and quickly changing slam events are not (Thomas et al., 2006).

For consistency in the units, the threshold value for the stress rate approach is taken as $\sigma_{\text {allow }} / \mathrm{dt}$, where $\mathrm{dt}$ is $1 / \mathrm{F}_{\mathrm{s}}$. Again, a sensitivity analysis of the effect of varying the stress rate threshold between $3.75 \%$ and $4.75 \%$ of $\sigma_{\text {allow }} / \mathrm{dt}$ in $0.25 \%$ increments on slam occurrence (see Section 5.3 for further verification). A sample whipping stress time record measured at strain gauge A, and its derivative, is presented in Figure 13.

Figure 13 Sample of slam detection using stress rate threshold at strain gauge location $A$ (peak and trough depicted by cross and asterisk)

\subsection{VISUAL INSPECTION}

As a means of verification of the whipping stress magnitude and rate approaches, and their associated threshold values, the stress time records measured at strain gauge location A were 
visually inspected. Visual inspection encompasses judging the stress record on the significance of the high frequency component and the decay after several oscillations.

Checks between the slam event times detected by each approach (in an algorithm) and by visual inspection were performed:

- $\quad \mathrm{i}=$ the number of slams in common

- $\quad$ ii $=$ the number of slams that were detected by the algorithm but not visually.

- $\quad$ iii $=$ the number of slams that were detected visually but not by the algorithm.

Further, the success of the whipping stress magnitude and derivative approaches was measured via an "efficiency metric", defined as the difference between the number of slams in common (i) and the number of slams that were found not to be in common (ii + iii) divided by the number of slams that were visually detected: efficiency $=(\mathrm{i}-\mathrm{ii}-\mathrm{iii}) /($ no. slams visually detected).

The results of the visual inspection, and the sensitivity of the slam occurrence to variation if the stress magnitude and rate thresholds, are presented in Table 4. For example, during the first hour in Set 1, 95 slam events were distinguishable by visual inspection. With the whipping stress magnitude threshold set to $1.95 \%$ of $\sigma_{\text {allow }}$ the algorithm detected 91 of these slams, though found an additional 25 slams and missed 4 slams. As such the efficiency for this threshold type and value was 0.65. In comparison, using the whipping stress derivative criterion set to $4 \%$ of $\sigma_{\text {allow }} / \mathrm{dt}$ the algorithm found 90 of the visually distinguishable slams, detected an additional 15 slams, and missed 5 slams. The efficiency for this threshold type and value was 0.76 .

In Table 4, the threshold for each criterion type that was the most efficient in detecting the slam occurrence for each hour is highlighted. In general, the whipping stress derivative was more efficient than the whipping stress magnitude at detecting slams, and the optimum threshold varied less with each hour. Overall, the optimum threshold of the whipping stress magnitude was $2.2 \%$ of $\sigma_{\text {allow. }}$. The optimum whipping stress rate threshold was $4 \%$ of $\sigma_{\text {allow }} / \mathrm{dt}$.

The approaches for slam identification are specific to one strain gauge in a certain vessel. This is because the structural response and operational profile of and naval high-speed craft, such as the ACPB, are quite distinct from conventional vessels (Magoga et al., 2015), and the structural response to slamming differs at different structural locations. To further demonstrate that selection of the sensor location is important for slamming detection, the whipping stress rate approach has been applied to the data measured by strain gauges $\mathrm{D}$ and $\mathrm{E}$ and the results are given in Table 5. As can be seen, the algorithm when applied to this response data does not successfully detect slams. This is attributed to the relatively small dynamic response of the structure further aft and at main deck level. For example, for the first hour 37 slams were visually distinguishable. With decreasing whipping stress rate threshold, though there is more commonality between the number of slams detected by both the algorithm and by eye, there are substantially more slams that are erroneously picked by the algorithm.

Therefore, this result reinforces the need to select an appropriate strain gauge location for effective slam detection.

Table 4 Comparison of visual inspection, whipping stress magnitude, and whipping stress rate approaches to define slam events based on strain gauge A data

Table 5 Comparison of visual inspection, and the whipping stress rate approach to define slam events based on strain gauges $D$ and $E$ data from Set 3 


\subsection{CRITERION BASED ON FATIGUE DAMAGE}

Similar to that proposed by Thomas et al. (2006), a slam criterion based on the fatigue damage incurred in a structural item is proposed. This method identifies the number of slam events that occurred during a period of time by calculating the difference in the number of stress cycles, above the fatigue limit of a structural item, between the total and wave-induced stress spectra. The number of slams is rounded to the nearest integer. The value of this method is that it is based on the effect of the slam on fatigue damage, rather than the dynamic response.

As an example, the wave-induced and total stress spectra at strain gauge location A during the first hour of Set 1 is presented in Figure 14. The fatigue limit of the construction item is also indicated in this figure.

\section{Figure 14 Histogram of wave-induced and total stress spectra at strain gauge location A during set 1 hour 1}

The fatigue damage criterion has been applied at all three datasets. The resulting number of wave-induced and total stress half-cycles, truncated below the fatigue limit, is provided in Table 6. For the first hour in Set 1, there were 19 more stress half-cycles above the fatigue limit in the total stress spectrum than in the wave-induced stress spectrum. Therefore, as the total stress spectrum includes whipping stresses, the estimated number of slam events that induced fatigue damage at strain gauge A location was rounded to 9 .

Table 6 Number of half cycles in wave-induced and total stress spectra above fatigue limit at strain gauge location A

\subsection{SUMMARY OF RESULTS}

A plot of the number of slams detected at strain gauge location A using the three approaches, and by visual inspection, for each hour considered is given in Figure 15.

Figure 15 Number of slams detected at strain gauge location A using different approaches

\section{DISCUSSION}

As shown in Figure 15 the number of slam events identified by the different methods varied. For the time records examined, the whipping stress magnitude of $2.2 \%$ of $\sigma_{\text {allow }}$ resulted in the detection of $17 \%$ more slam events than found by visual inspection. Using the whipping stress rate threshold of $4 \%$ of $\sigma_{\text {allow }} / \mathrm{dt}$, the difference in the slam occurrence relative to visual observation was $6 \%$. The fatigue damage criterion was the least successful, fining only $13 \%$ of the slams found visually.

The benefit of slam identification methods based on stress magnitude and stress rate is that the time at which a slam event is known, and it can be implemented as near real-time structural response feedback to the operator. Therefore, the effect of parameters such as speed, heading, and wave height on the number and severity of individual slam events can be related. However, the threshold values chosen somewhat arbitrarily result in a subset of data being treated as slam events. For use of this subset to characterise slam events (e.g. in terms of severity, damping, etc.), it is possible that a different threshold would produce different results. On the other hand the fatigue damage criterion is based on a defined limit, providing that the fatigue strength and construction detail of a structural item are known. At this stage, 
the fatigue damage method is limited to computing the number of slams occurring in a given period, the severity of the stress cycle rather than the stress magnitude, and it assumes that one fatigue-contributing stress cycle equates to one slam event. That is, the method does not account for several stress oscillations exceeding the fatigue limit within one slam event. With incorporation of a technique to time-stamp stress half-cycles that contribute to fatigue, it may be possible to better characterise slam events differentiated via fatigue damage induced by the high frequency response.

Though sets of data representative of different vessel speeds, headings, encounter frequency and sea state were analysed, the applicability of the thresholds to all operational conditions has not been tested. A next step is to use the slam detection approach to investigate the sensitivity of both slam occurrence and severity to encounter frequency, speed, and wave height.

As the approaches considered rely on measured response data, sources of uncertainty are introduced by the measurement process. A level of broad spectrum noise appears to be present in the strain data, which varies from gauge to gauge, and may be attributed to noise in the amplification system. There is also a contribution to the signal from induced electrical noise.

When planning installation of a HMS onboard a naval platform, it is important that sensors are located to meet the aims of the project: install strain gauges along the length of vessel to understand global wave loads; install strain gauges in the vicinity of highly stressed or cracking prone areas to understand fluctuating stresses that induce fatigue damage, and; install strain gauges (preferably an array) at the forward bottom section of the hull to obtain the structural response to impacts. For the last aim the gauge(s) should be located away from bending nodes to ensure that structural excitation is measured. This can checked via modal analysis. Ease of access to the structure also needs to be considered. A balance between the costs associated with setting-up and maintaining hardware plus processing and analysing large quantities of data, and the number of sensors installed, needs to be determined.

\section{CONCLUSION}

This paper has presented an investigation into different approaches to identify slam events using strain measurement data of an in-service naval high-speed craft. Hull monitoring data measured onboard a RAN ACPB, during which the vessel experienced relatively high stresses, were considered. To examine the individual stress components, the total stress was decomposed into the wave- and slam-induced (whipping) contributions. Using spectral density estimations of the measured strain records at four strain gauge locations, the waveinduced and whipping were separated by the cut-off frequency between the low and high frequency response. Differences in the whipping component of the stress time records were observed at different locations. At the bottom gauge locations, the impulsive loading of the slam imparted sufficient energy to excite high-frequency stress oscillations. In demonstrating the importance of high frequency hull-girder response for fatigue damage estimation of the $\mathrm{ACPB}$, it was found that the contribution of whipping stresses to the fatigue damage ranged from $35 \%$ to $57 \%$ for the hourly records and strain gauges analysed.

Three ship-specific approaches to identify slam events in the measured strain data were examined. For the hull monitoring data considered, in general, it was found that both the whipping stress magnitude and rate definitions successfully detected slams, visually distinguishable in the high frequency stress component by a relatively large amplitude rise followed by multiple decaying oscillations. 
The necessary elements for a slamming-related operator guidance procedure appropriate to a naval high speed craft are available. To provide near real-time slam event information to the operator, use of the stress rate criterion appears to be favourable. However, for a particular vessel future users should conduct a sensitivity analysis to find and verify the appropriate threshold and sensor locations.

\section{FURTHER WORK}

As noted by a number of researchers as well as the work presented in this paper, the boundary between whether or not a slam occurs is imprecise. DST Group plans to conduct sea trials in which slam pressures will be attempted to be measured by pressure transducers as part of a HMS installed onboard a second ACPB. It is envisioned that the hydrodynamic pressures recorded by the pressure transducers may facilitate another means to detect slams and verify slam counting algorithms discussed in the paper. However, due to practical challenges associated with installing pressure sensors in an operational vessel, this method is unlikely to be used extensively.

Incorporation of a bridge warning system which will provide information on the structural health of the vessel into the existing ACPB HMS is also an area of high interest. It is envisioned that the work presented here on the slam detection, upon verification by sea trials structural response measurement and analysis, can provide suitable feedback to the operator as part of a bridge warning system.

\section{ACKNOWLEDGEMENTS}

The assistance of DST Group staff involved with the HMAS GLENLEG sensor network is appreciated.

\section{REFERENCES}

2013. MAESTRO 11.0.0. Advanced Marine Technology Center, DRS Defense Solutions, Stevensville, USA.

Aksu, S., Magoga, T., Riding, B., 2015. Analysis of HMAS GLENELG's Onboard Structural Monitoring Data, Pacific 2015 International Maritime Conference, Sydney, Australia.

Barhoumi, M., Storhaug, G., 2013. Assessment of Whipping and Springing on a Large Container Vessel, 12th International Symposium on Practical Design of Ships and Other Floating Structures, Changwon City, South Korea.

Carrera, G., Rizzo, C., 2005. Measurements of Motions, Loads and Structural Response on a Fast FRP Pleasure Craft, International Conference on Fast Sea Transportation, FAST'2005, St. Petersburg, Russia.

Colwell, J., Stredulinsky, D., 2008. Seakeeping Operator Guidance, Pacific 2012 International Maritime Conference, Sydney, Australia.

Ćorak, M., Parunov, J., Guedes Soares, C., 2013. Long-term prediction of combined wave and whipping bending moments of container ships. Ships and Offshore Structures.

Dessi, D., Ciappi, E., 2013. Slamming clustering on fast ships: From impact dynamics to global response analysis. Ocean Engineering 62, 110-122. 
DRS Defense Solutions, 2011. MAESTRO Manual. DRS Defense Solutions, Stevensville, USA.

French, B., 2012. Slamming of Large High-Speed Catamarans in Irregular Seas. University of Tasmania, Launceston, Australia.

Gardiner, C., Vincent, P., Wilson, A., Ellery, D., Armstrong, T., 2008. A trial sensor network for the Armidale Class patrol boat, International Maritime Conference, Pacific 2008, Sydney, Australia, pp. 504-514.

Gudze, M., Flockhart, C., Cannon, S., 2006. Short Term Damage Assessment in Naval Ship Structures, Pacific 2006 International Maritime Conference, Sydney, Australia.

Hughes, O., Paik, J., 2010. Ship Structural Analysis and Design. The Society of Naval Architects and Marine Engineers, Jersey City, USA.

Ito, Y., Nielsen, U., Jensen, J., 2010. Estimation of Fatigue Damage from Full-Scale Measurements of Hull Girder Stresses, 11th International Symposium on Practical Design of Ships and Other Floating Structures, Rio de Janeiro, Brazil.

Kramer, R.H., Haugan, G., Fredriksen, A., 2006. US navy high speed craft - Comparison of ABS and DNV structural requirements. Transactions - Society of Naval Architects and Marine Engineers 113, 340-366.

Kwon, K., Frangopol, D., Kim, S., 2012. Fatigue performance assessment and service life prediction of high-speed ship structures based on probabilistic lifetime sea loads. Structure and Infrastructure Engineering 9 (2), 102-115.

Magoga, T., Aksu, S., Cannon, S., Ojeda, R., Thomas, G., 2015. The Need for Fatigue Life Prediction Methods Tailored to High-Speed Craft: A Technical Review, Pacific 2015 International Maritime Conference, Sydney, Australia.

Mansour, A., Liu, D., 2008. Strength of Ships and Ocean Structures. The Society of Naval Architects and Marine Engineers, Jersey City, USA.

Miner, M., 1945. Cumulative Fatigue in Damage. Journal of Applied Mechanics 12, 159-164.

Nielsen, U., Jensen, J., Pedersen, P., Ito, Y., 2011. Onboard monitoring of fatigue damage rates in the hull girder. Marine Structures 24, 182-206.

Ochi, M., 1964. Prediction of the occurrence and severity of ship slamming at sea, 5 th Symposium on Naval Hydrodynamics, Bergen, Norway.

Rychlik, I., 1987. A new definition of the rainflow cycle counting method. International Journal of Fatigue 9 (2), 119-121.

Sielski, R., 2008. Research Needs in Aluminum Structures. Ships and Offshore Structures 3 (1), 57-65.

Technical Committee CEN/TC 250, 1999. Eurocode 9: Design of aluminium structures. British Standards, Brussels, Belgium. 
Thomas, G., Davis, M., Holloway, D., Roberts, T., 2006. The Effect of Slamming and Whipping on the Fatigue Life of a High-Speed Catamaran. Australian Journal of Mechanical Engineering 3 (2), 165-174.

Thomas, G., Davis, M., Holloway, D., Watson, N., Roberts, T., 2003. Slamming Response of a Large High-Speed Wave-Piercer Catamaran. Marine Technology 40 (2), 126-140.

Vincent, P., Gardiner, C., Wilson, A., Ellery, D., Armstrong, T., 2008. Installation of a sensor network on an RAN Armidale Class Patrol Boat. Materials Forum 33, 307-316.

Zhu, J., Collette, M., 2011. Lifecycle Fatigue Management for High-Speed Vessels Using Local Approaches, 11th International Conference on Fast Sea Transportation, Honolulu, USA. 


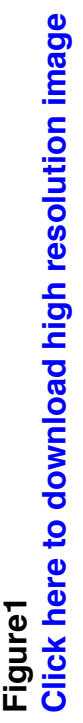

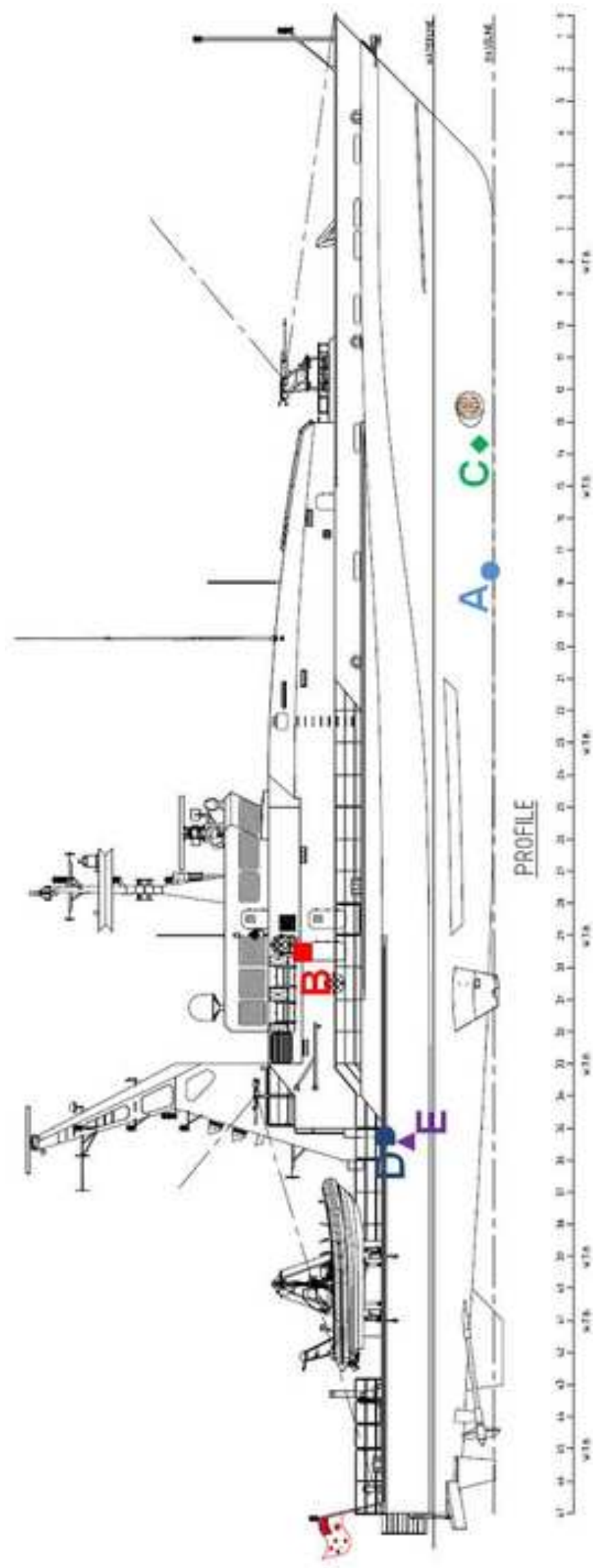




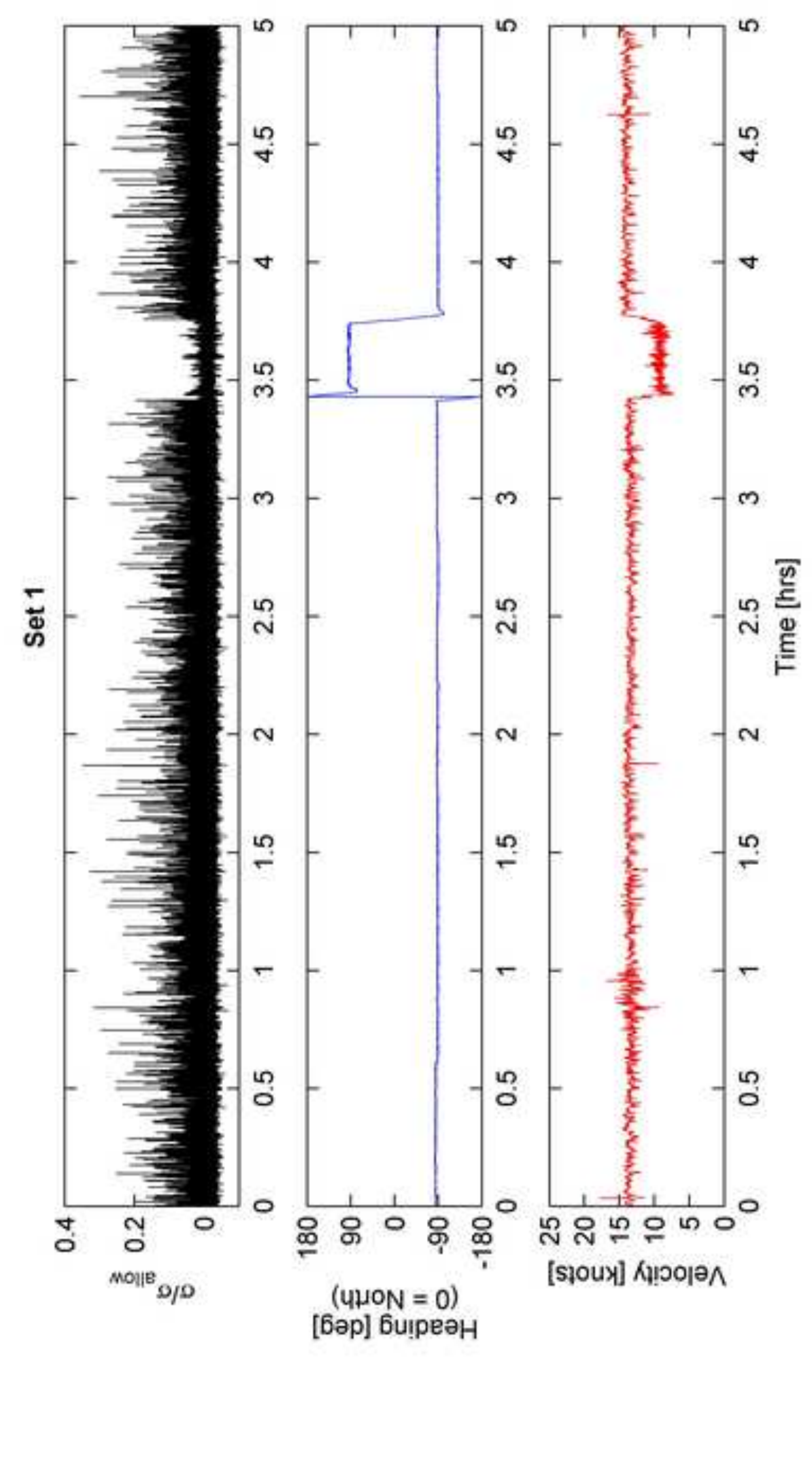




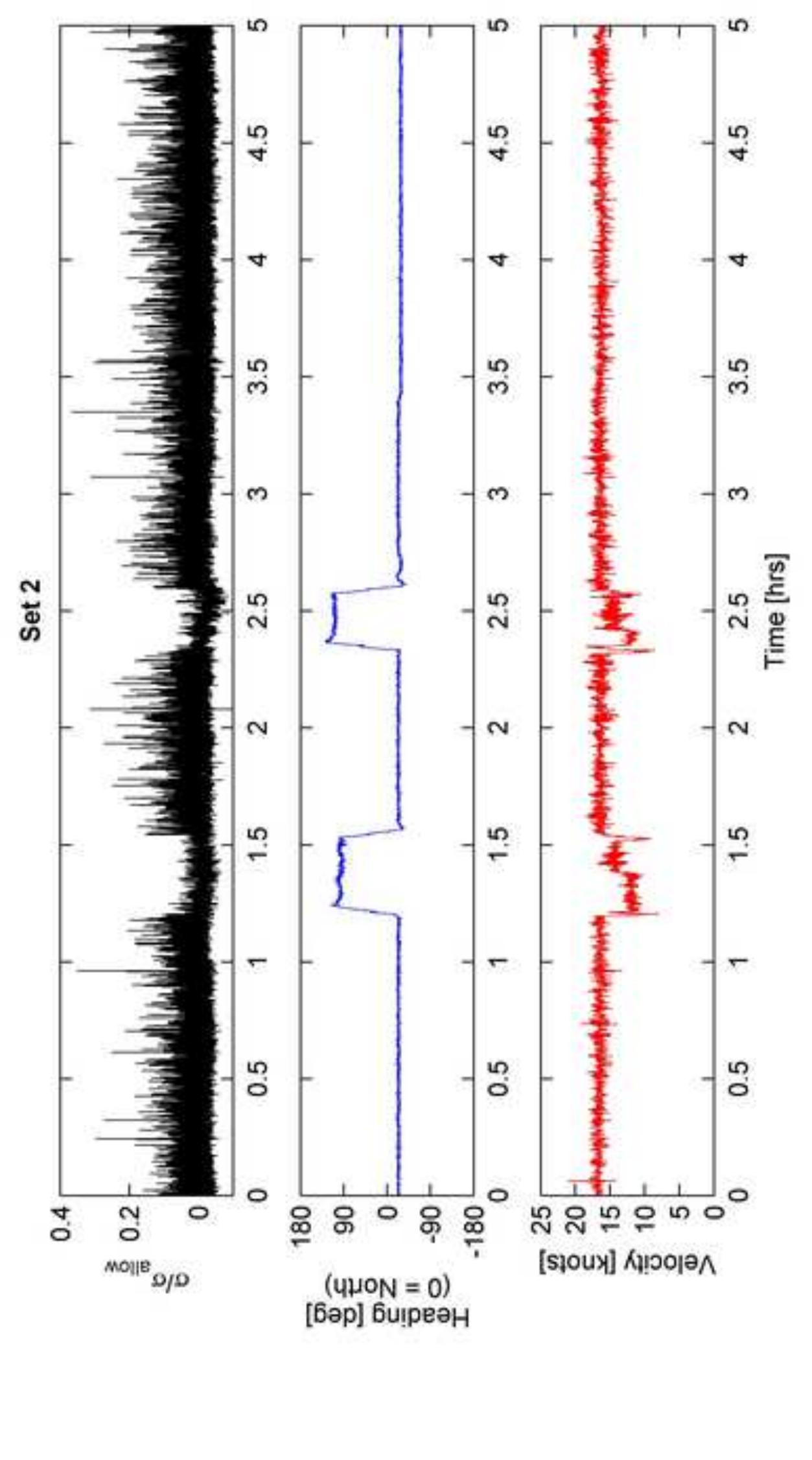




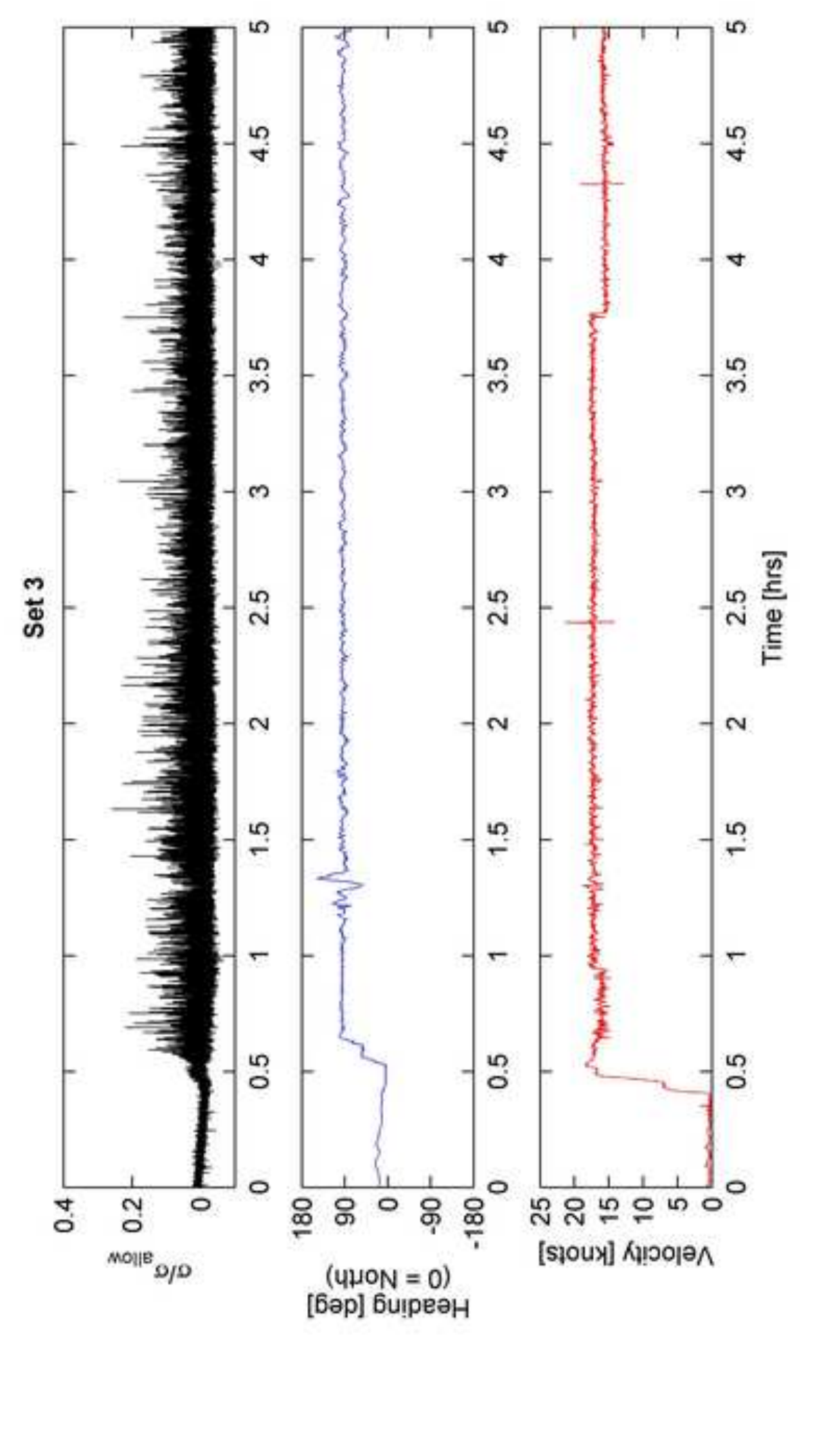




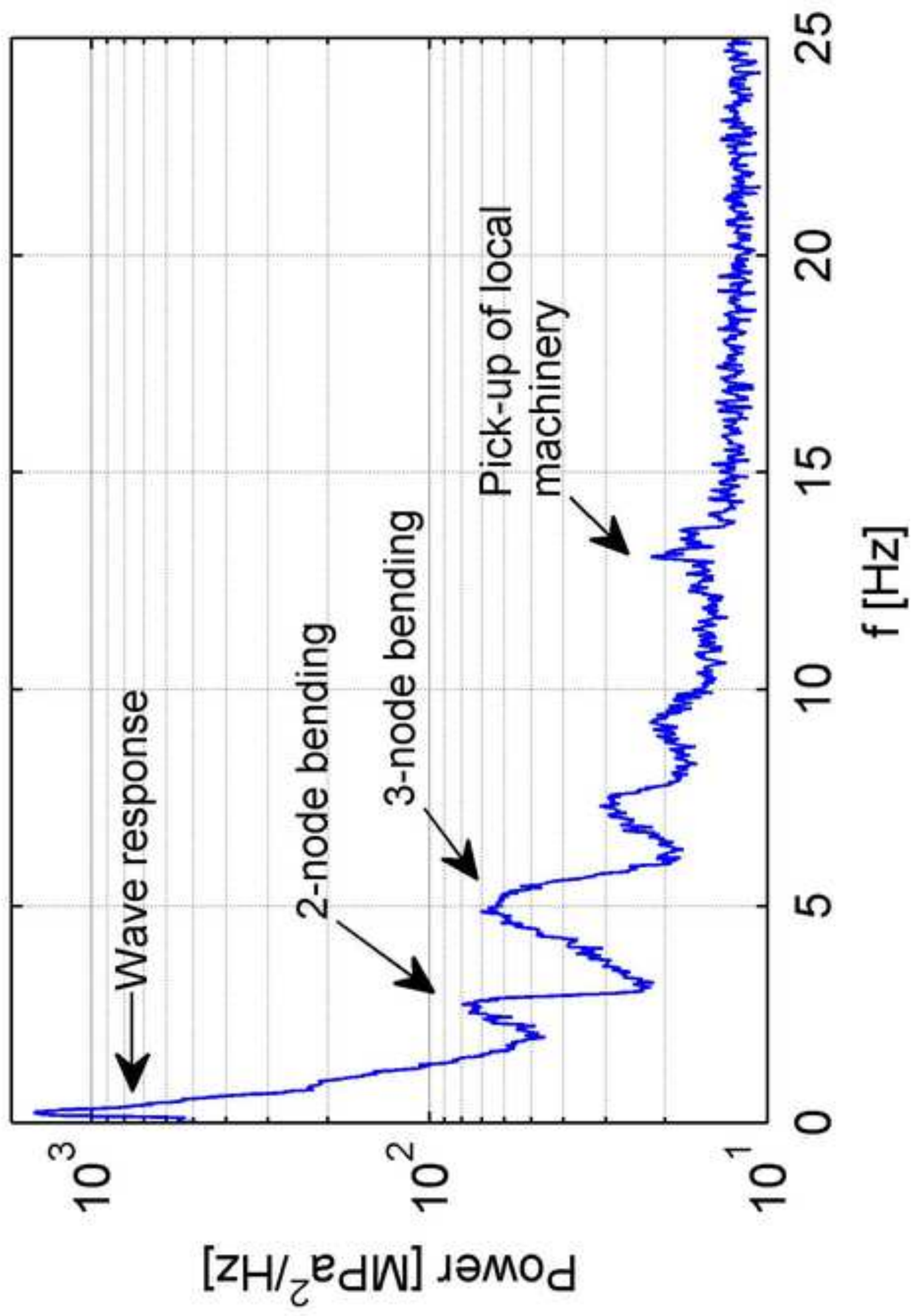

๑)

通衣 

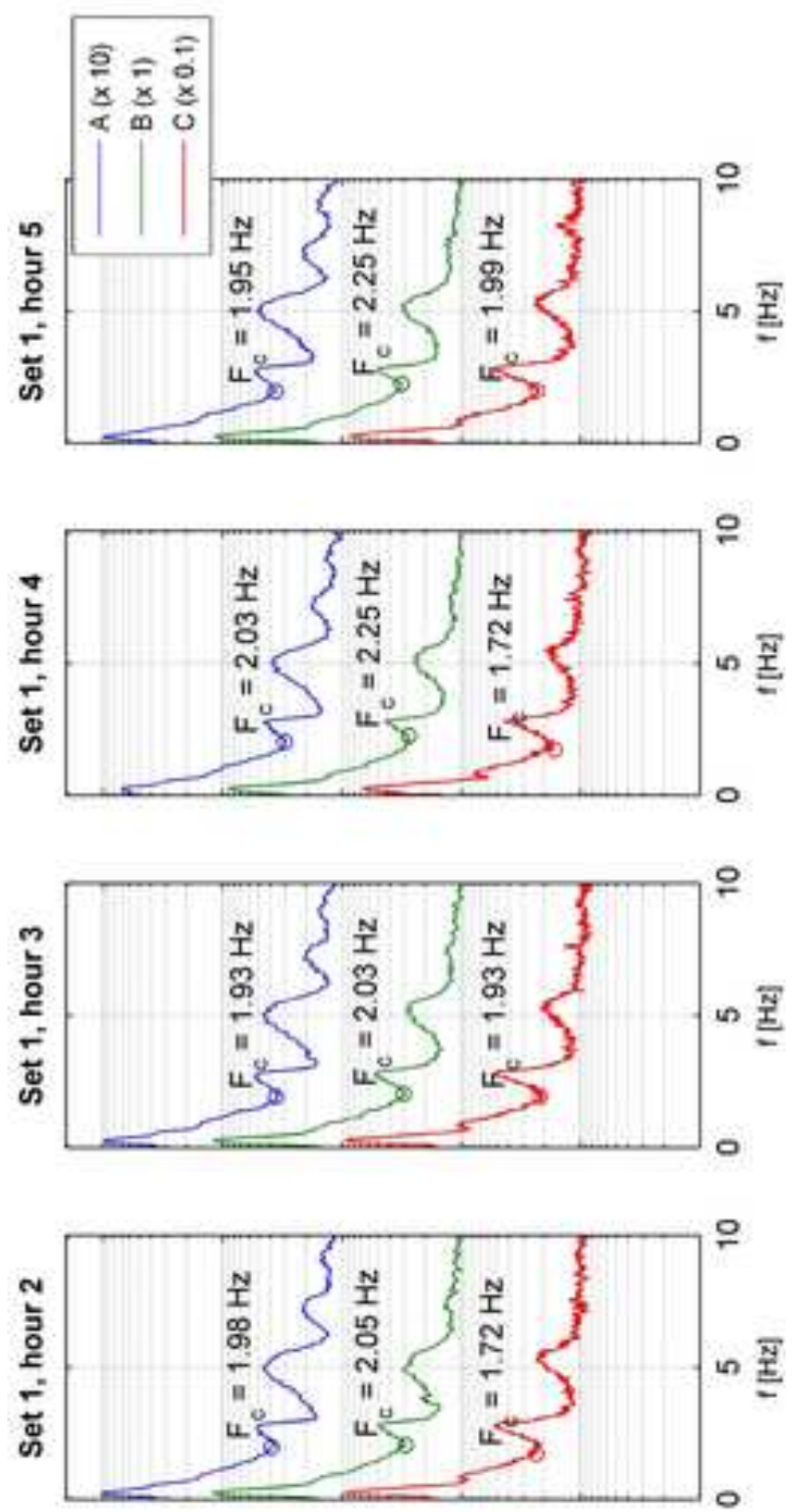

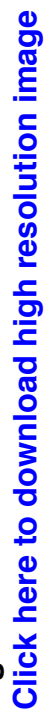

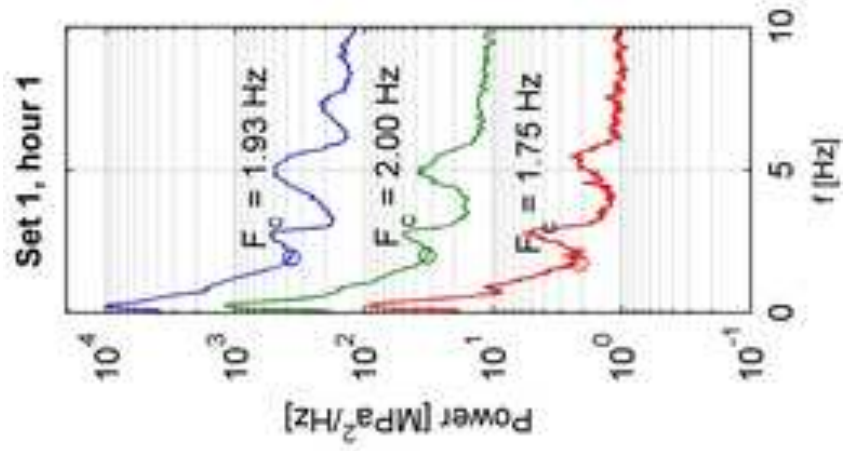




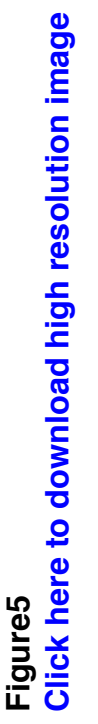

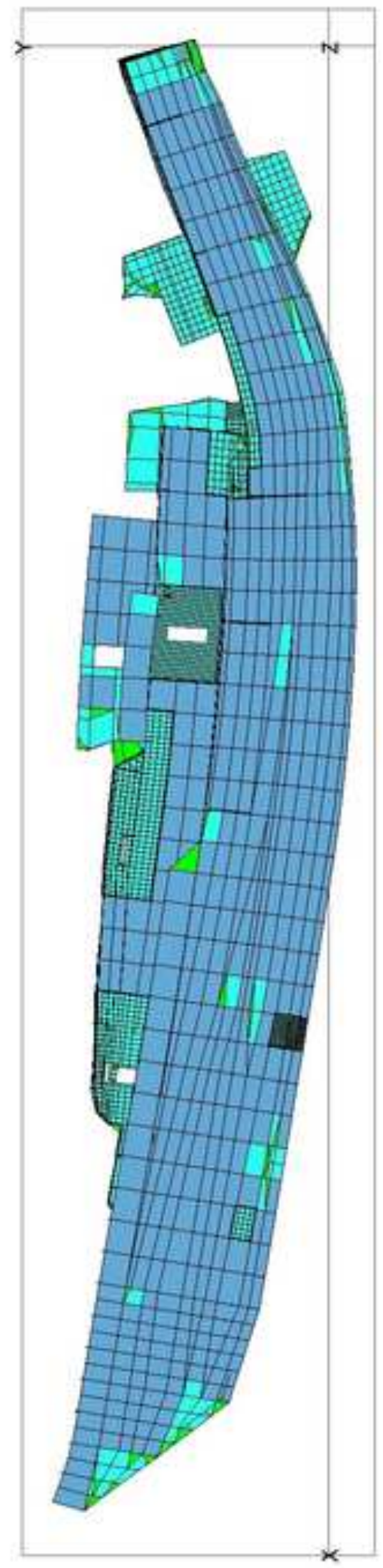




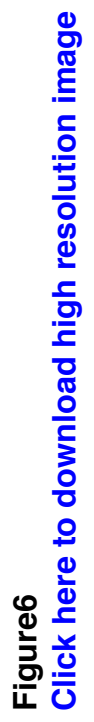

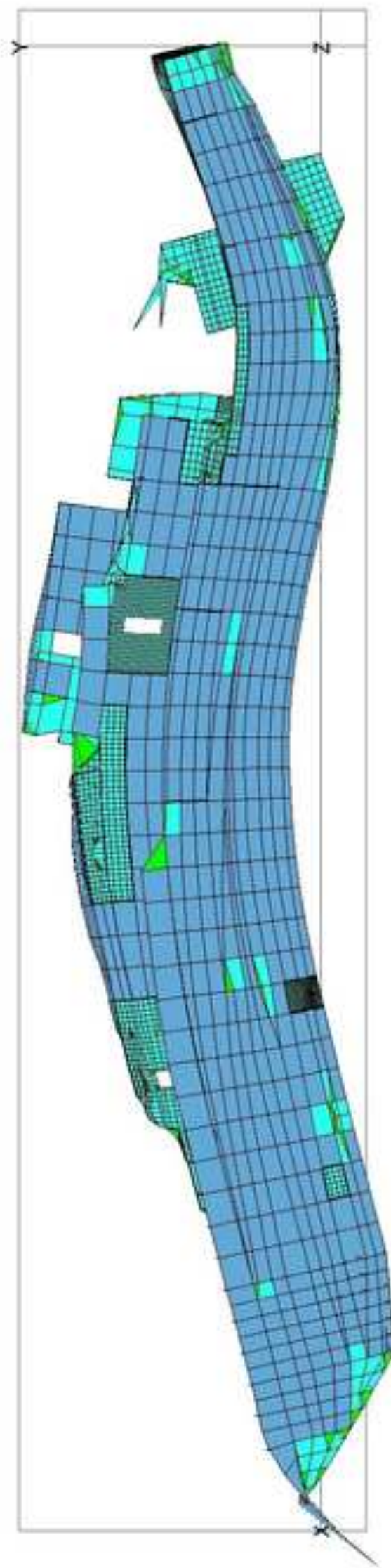




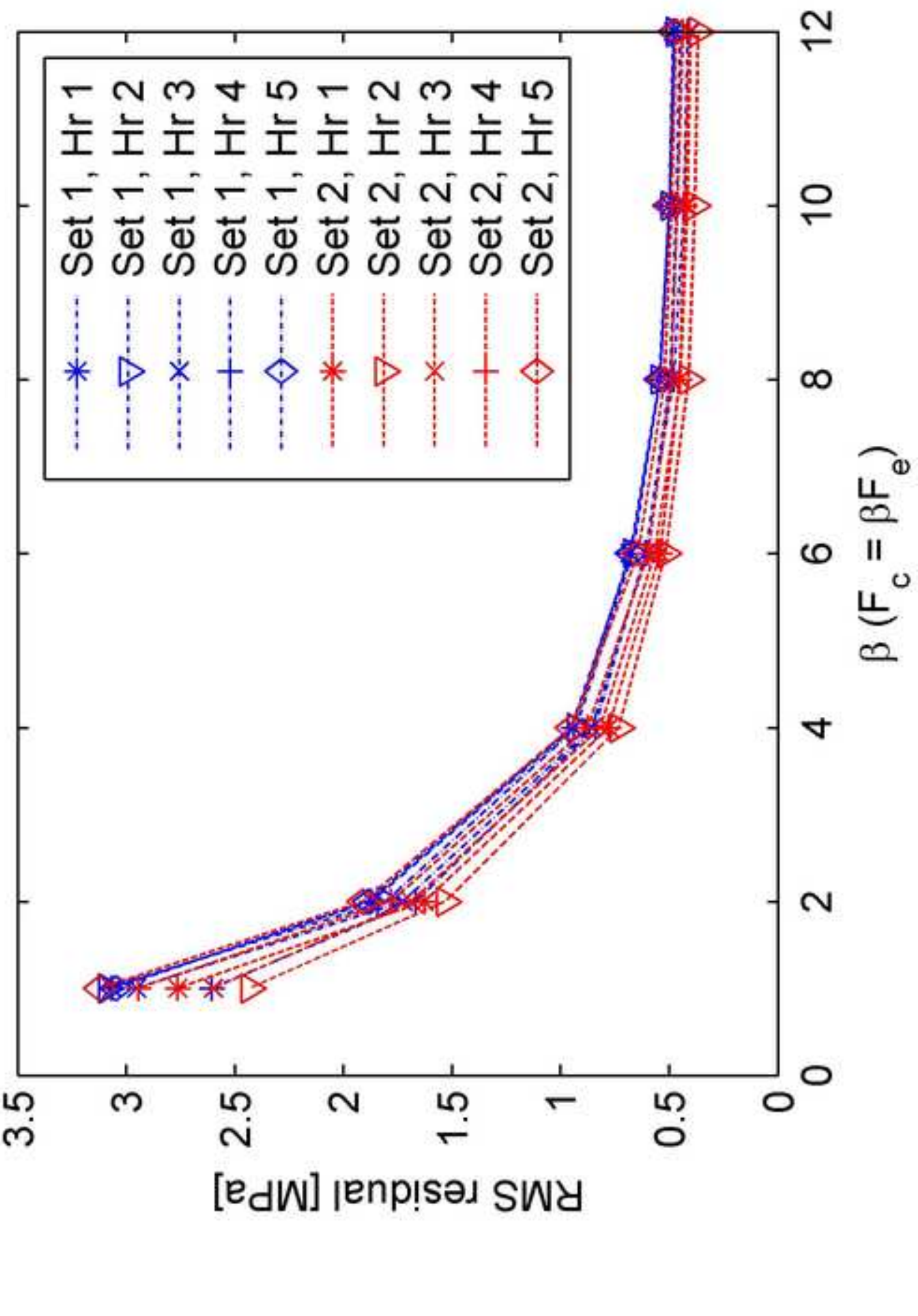




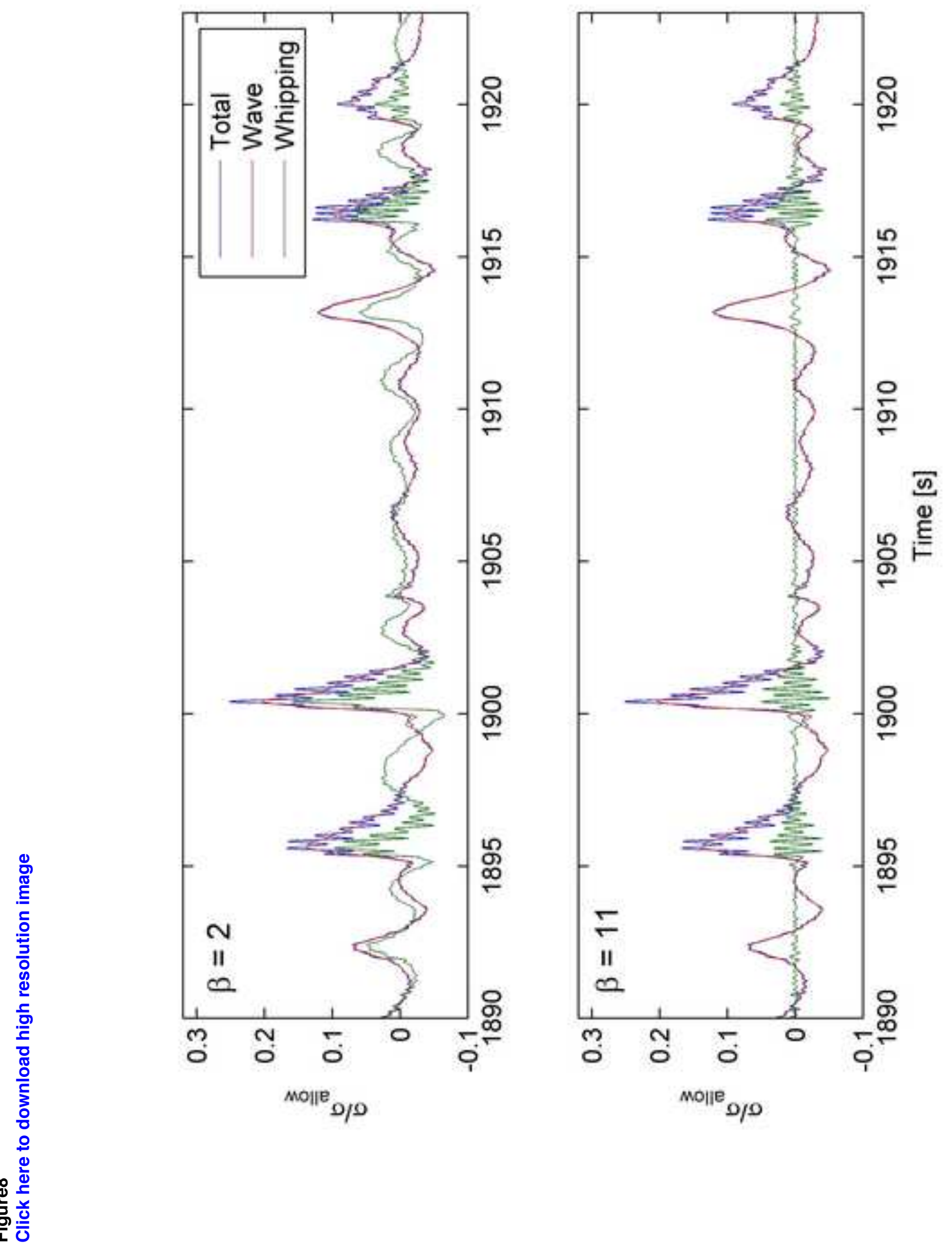




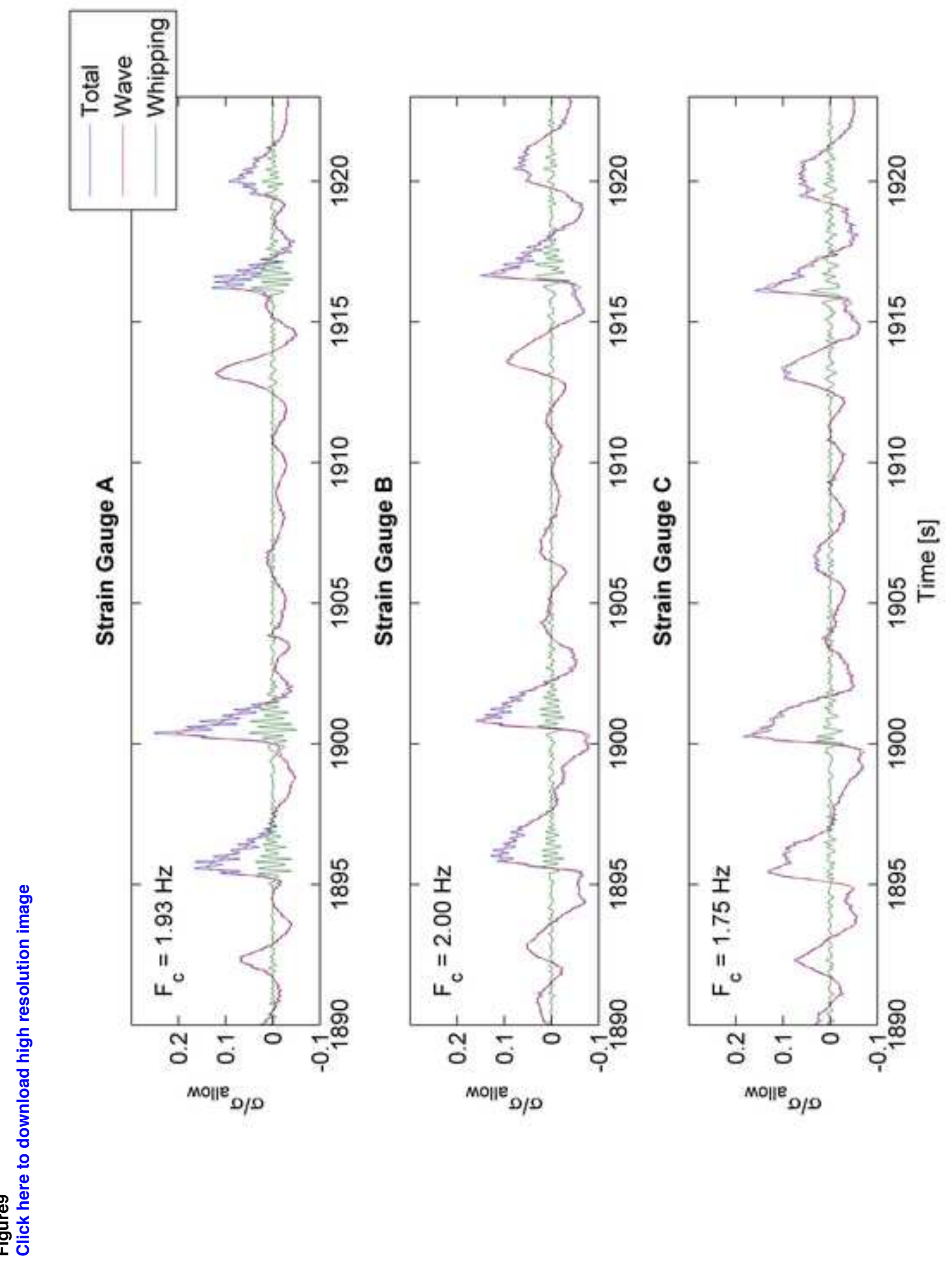



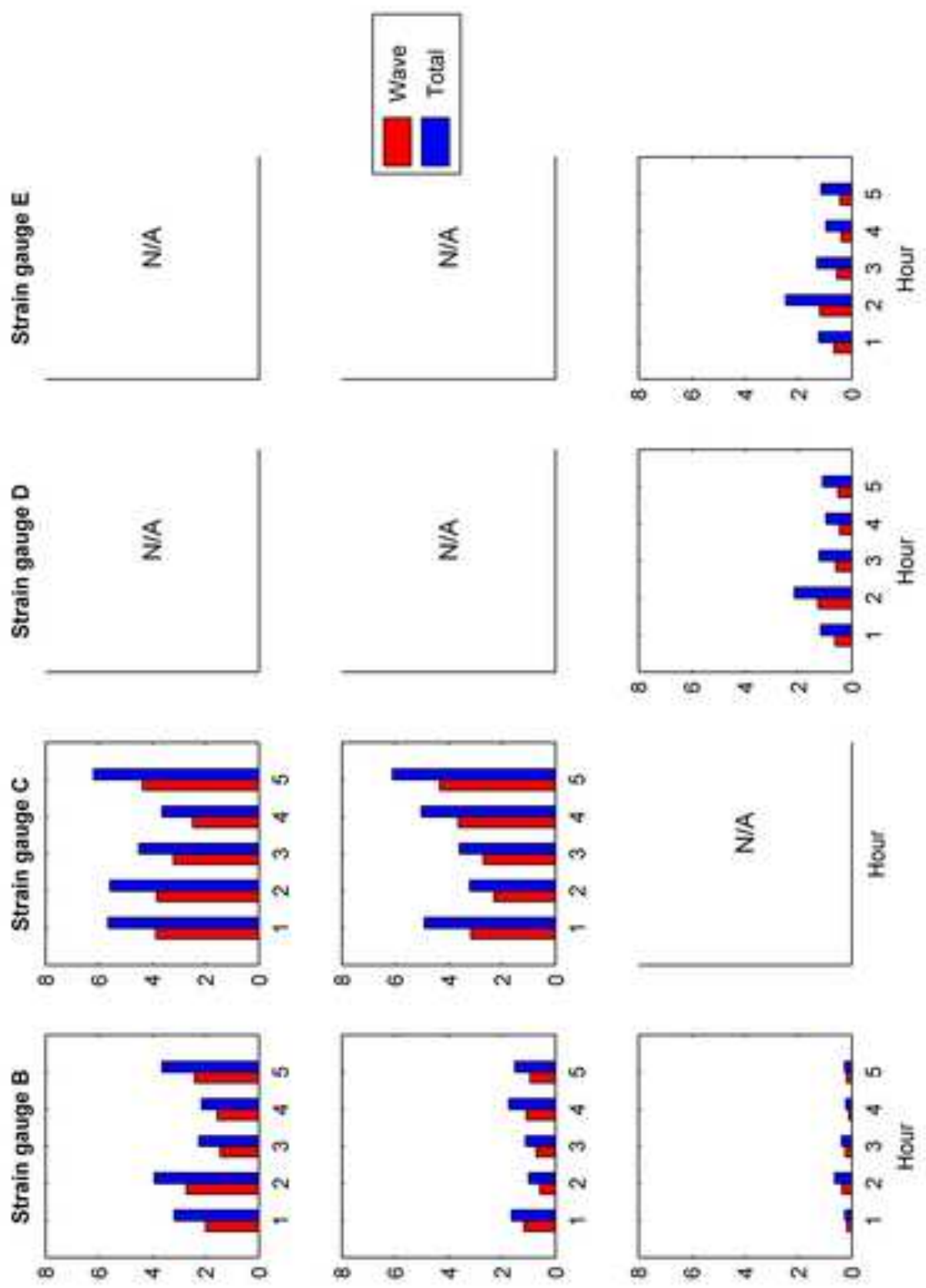

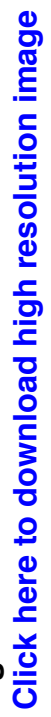

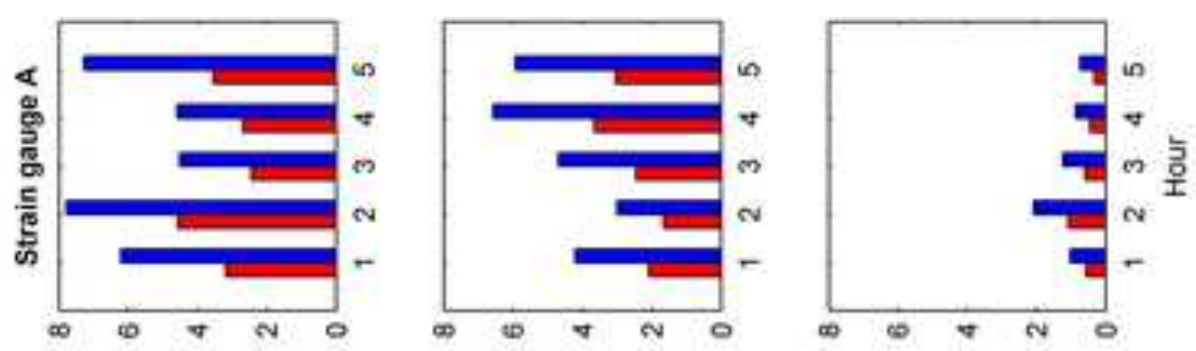

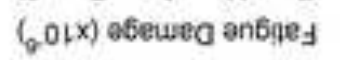

L 1 as

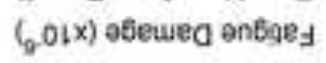

zias
GoLx) obeureg enbiges

$\varepsilon$ ł S 


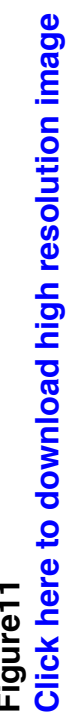

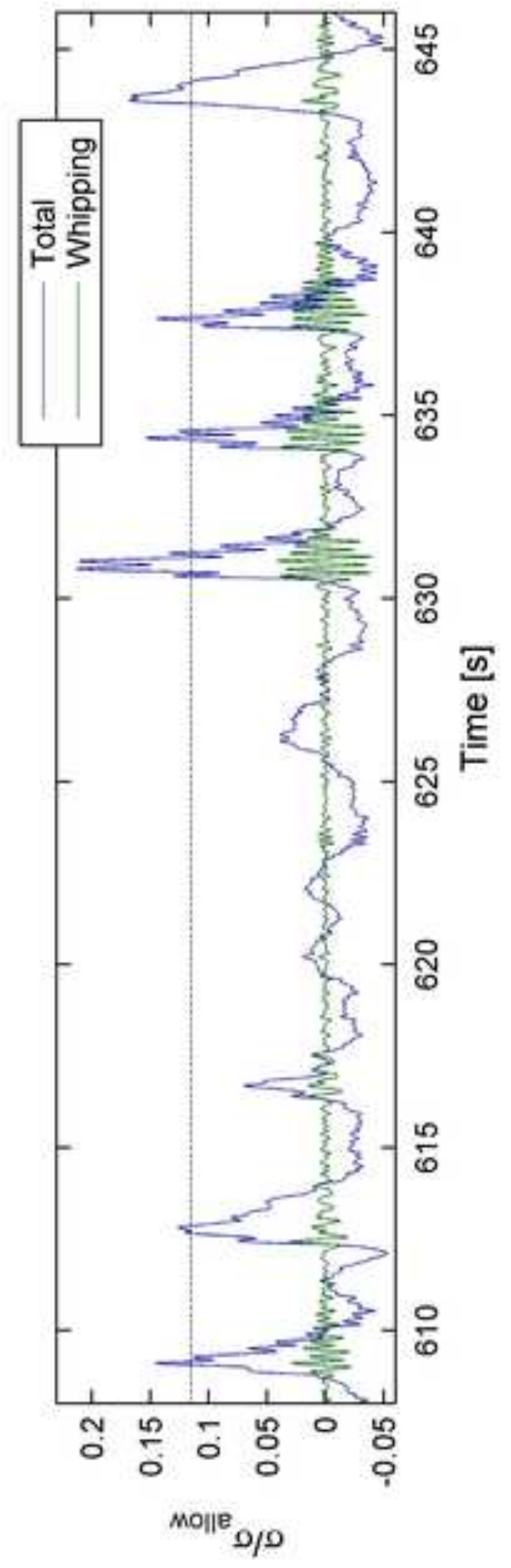




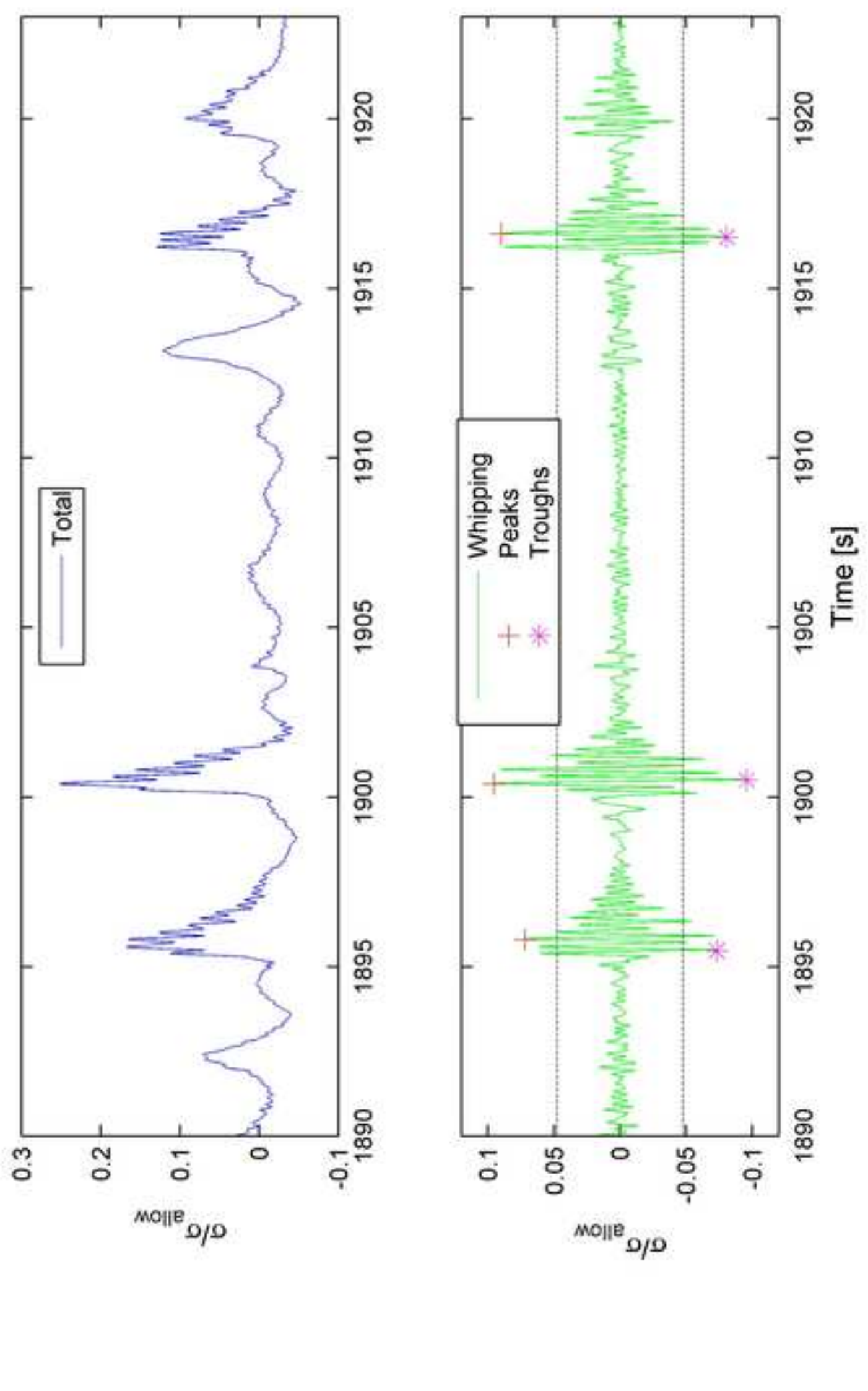




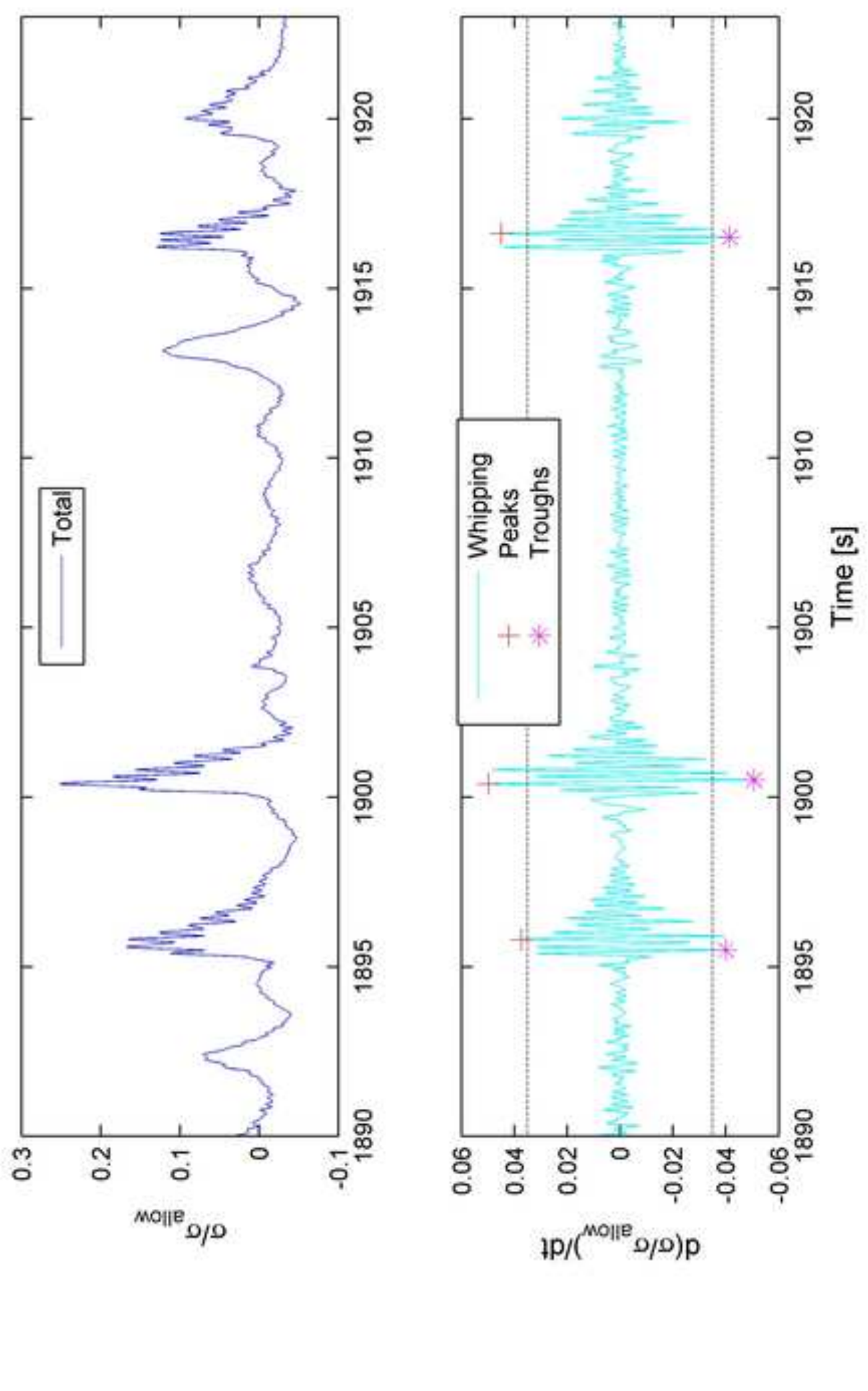




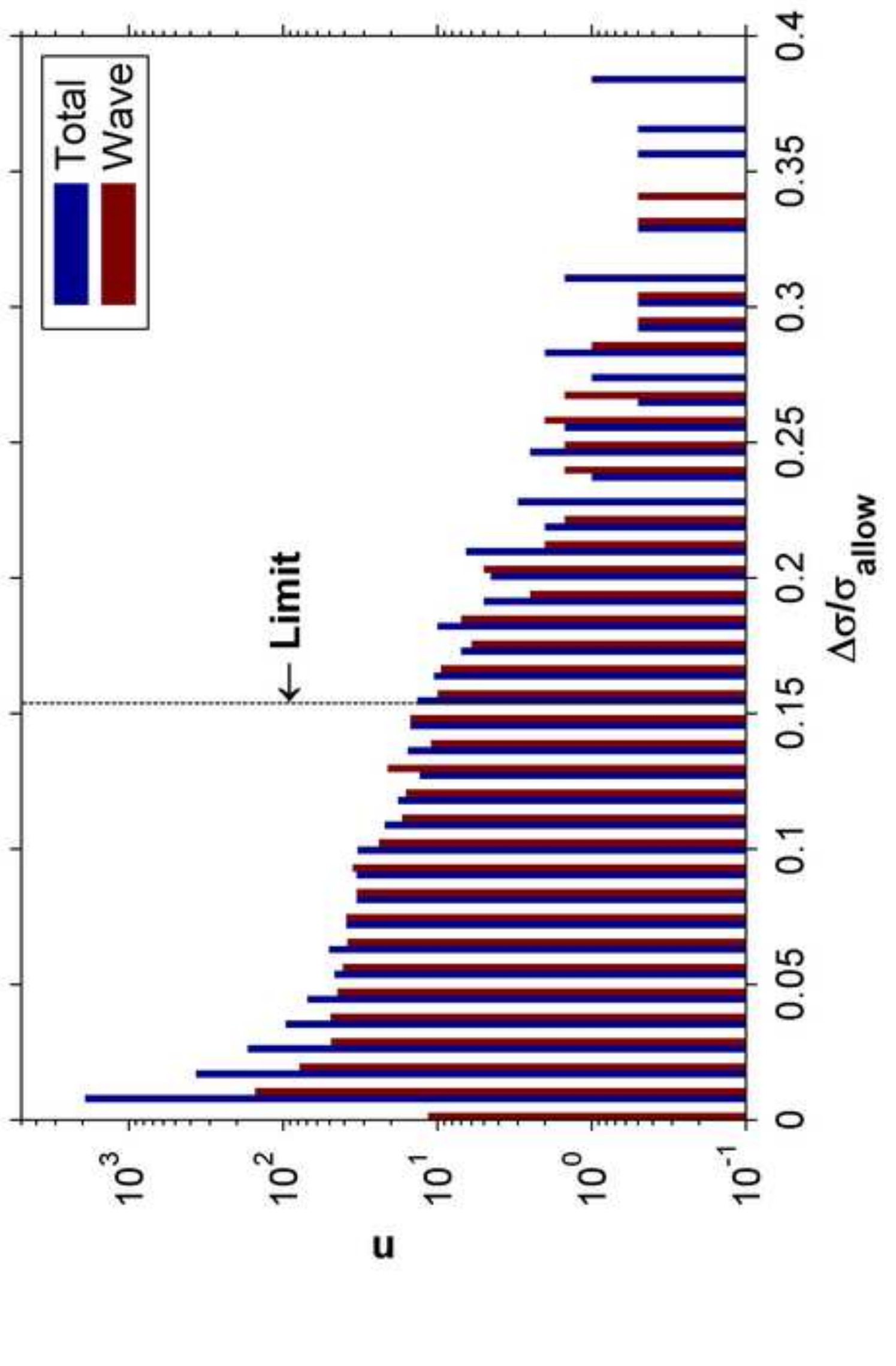


No. of slams

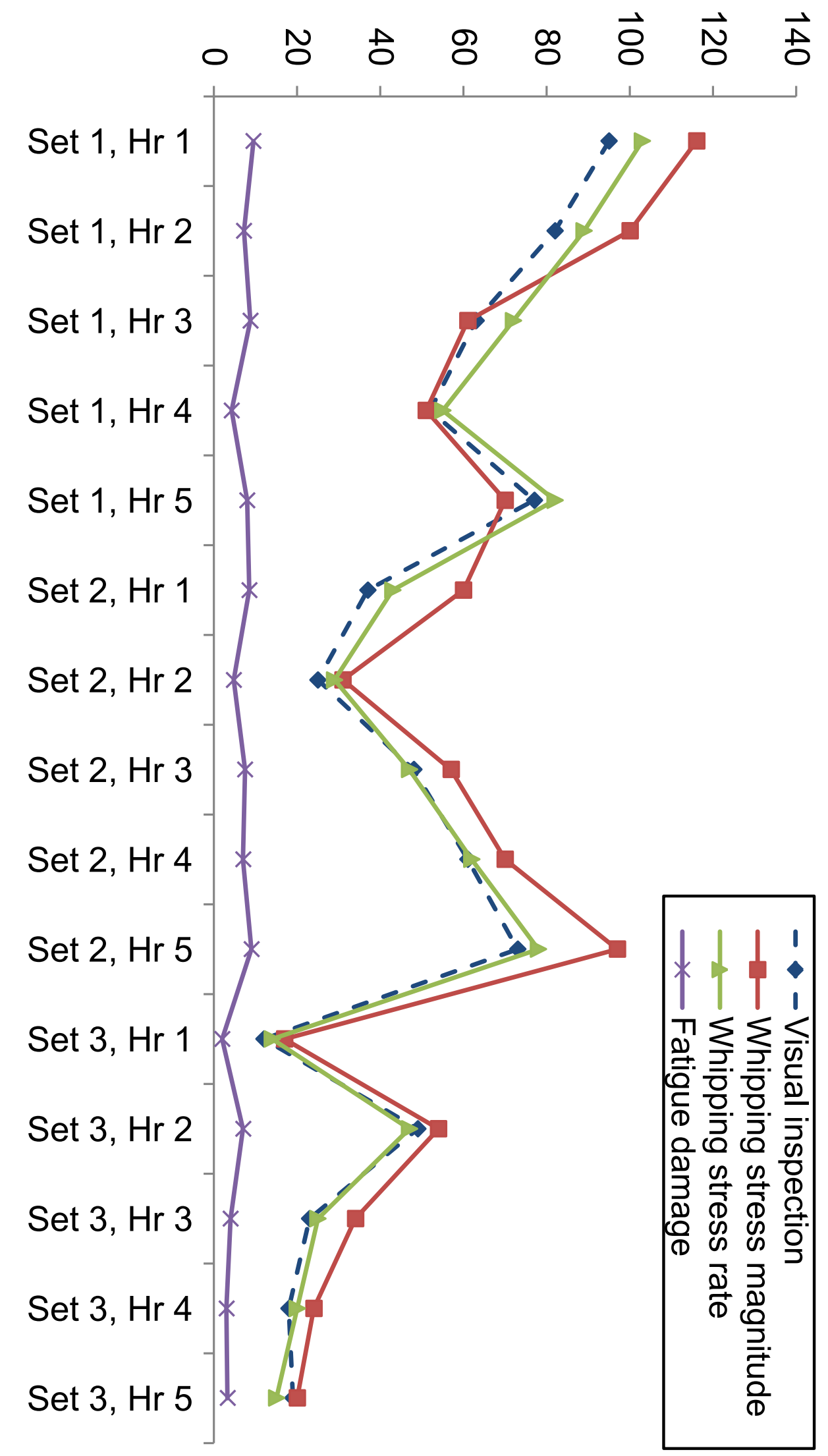




\begin{tabular}{|c|c|}
\hline $\begin{array}{l}\text { Strain } \\
\text { Gauge }\end{array}$ & Approximate Location \\
\hline A & $\begin{array}{c}\text { On centre of flange of bottom centreline girder, } 19.8 \mathrm{~m} \text { aft of } \\
\text { forward perpendicular (FP) }\end{array}$ \\
\hline B & $\begin{array}{l}\text { On sideshell plating } 0.2 \mathrm{~m} \text { below bridge deck, } 33.8 \mathrm{~m} \text { aft of } \\
\text { FP }\end{array}$ \\
\hline $\mathrm{C}$ & $\begin{array}{l}\text { On centre of flange of } 4 \text { th stiffener from CL girder on port } \\
\text { side, } 20.0 \mathrm{~m} \text { aft of FP }\end{array}$ \\
\hline $\mathrm{D}$ & $\begin{array}{l}\text { On deck plating } 42.6 \mathrm{~m} \text { aft of FP, approximately } 0.45 \mathrm{~m} \\
\text { inboard from deck edge (between two outermost stiffeners) }\end{array}$ \\
\hline $\mathrm{E}$ & $\begin{array}{c}\text { On centre of flange of stiffener underside of main deck, } 3.65 \\
\mathrm{~m} \text { off CL, } 42.6 \mathrm{~m} \text { aft of FP (and } 0.6 \mathrm{~m} \text { aft of a pillar) }\end{array}$ \\
\hline
\end{tabular}


Computed Measured Diff.

\begin{tabular}{llll}
\hline 2-node [Hz] & 2.4 & 2.5 & $4 \%$ \\
3-node [Hz] & 4.6 & 5.0 & $7 \%$ \\
\hline
\end{tabular}




\begin{tabular}{|c|c|c|c|}
\hline $\begin{array}{c}\text { Strain } \\
\text { Gauges }\end{array}$ & Eurocode 9 Detail Type & $\begin{array}{c}\text { Fatigue } \\
\text { limit [MPa] }\end{array}$ & Justification \\
\hline C \& D & $\begin{array}{c}7.2 .1 \text { - welded from both } \\
\text { sides using full penetration } \\
\text { welding on flat solid }\end{array}$ & 25.1 & $\begin{array}{c}\text { Strain gauges are on plating, in the } \\
\text { vicinity of butt-welded joints that are } \\
\text { assumed to be welded from both sides. } \\
\text { A crack that initiates is assumed to be } \\
\text { due to a flaw or discontinuity in the } \\
\text { weld. }\end{array}$ \\
\hline A, B \& & $\begin{array}{c}\text { E } \\
\text { E }\end{array}$ & $\begin{array}{c}\text { At weld discontinuity } \\
\text { of }\end{array}$ & $\begin{array}{c}\text { Strain gauges are located on the flange } \\
\text { of longitudinal girders, joined to the } \\
\text { web of the girders using a continuous } \\
\text { fillet weld. The dominant load } \\
\text { direction (longitudinal) is in-line with } \\
\text { the weld. Again, a crack that initiates } \\
\text { is assumed to be due to a flaw or } \\
\text { discontinuity in the weld. }\end{array}$ \\
\hline
\end{tabular}


Table4

\begin{tabular}{|c|c|c|c|c|c|c|c|c|c|c|c|c|c|}
\hline \multirow{2}{*}{ Set } & \multirow{2}{*}{ Hour } & \multirow{2}{*}{ Check Type } & \multicolumn{5}{|c|}{ Whipping stress magnitude ( $\%$ of $\sigma_{\text {allow }}$ ) } & \multicolumn{5}{|c|}{ Whipping stress derivative (\% of $\sigma_{\text {allow }} / \mathbf{d t}$ ) } & \multirow{2}{*}{$\begin{array}{c}\text { Visual } \\
\text { detection }\end{array}$} \\
\hline & & & $2.45 \%$ & $2.20 \%$ & $1.95 \%$ & $1.70 \%$ & $1.45 \%$ & $4.75 \%$ & $4.50 \%$ & $4.25 \%$ & $4.00 \%$ & $3.75 \%$ & \\
\hline \multirow{20}{*}{1} & \multirow{4}{*}{1} & $\mathrm{i}$ & 59 & 76 & 91 & 94 & 95 & 59 & 67 & 75 & 90 & 93 & \multirow{4}{*}{95} \\
\hline & & ii & 4 & 11 & 25 & 42 & 89 & 2 & 4 & 9 & 13 & 21 & \\
\hline & & iii & 36 & 19 & 4 & 1 & 0 & 36 & 28 & 20 & 5 & 2 & \\
\hline & & Efficiency & 0.20 & 0.48 & 0.65 & 0.54 & 0.06 & 0.22 & 0.37 & 0.48 & 0.76 & 0.74 & \\
\hline & \multirow{4}{*}{2} & i & 52 & 67 & 78 & 80 & 82 & 54 & 59 & 71 & 78 & 80 & \multirow{4}{*}{82} \\
\hline & & ii & 2 & 6 & 22 & 44 & 85 & 1 & 2 & 4 & 11 & 21 & \\
\hline & & iii & 30 & 15 & 4 & 2 & 0 & 27 & 22 & 11 & 4 & 2 & \\
\hline & & Efficiency & 0.24 & 0.56 & 0.63 & 0.41 & -0.04 & 0.32 & 0.43 & 0.68 & 0.77 & 0.70 & \\
\hline & & i & 40 & 46 & 56 & 60 & 61 & 40 & 46 & 56 & 60 & 61 & \\
\hline & 3 & ii & 2 & 2 & 5 & 12 & 20 & 2 & 2 & 5 & 12 & 20 & 63 \\
\hline & 3 & iii & 23 & 17 & 7 & 3 & 2 & 23 & 17 & 7 & 3 & 2 & \\
\hline & & Efficiency & 0.24 & 0.43 & 0.70 & 0.71 & 0.62 & 0.24 & 0.43 & 0.70 & 0.71 & 0.62 & \\
\hline & & $\mathrm{i}$ & 36 & 41 & 47 & 49 & 52 & 36 & 41 & 47 & 49 & 52 & \\
\hline & & ii & 0 & 0 & 4 & 6 & 14 & 0 & 0 & 4 & 6 & 14 & 52 \\
\hline & 4 & iii & 16 & 11 & 5 & 3 & 0 & 16 & 11 & 5 & 3 & 0 & \\
\hline & & Efficiency & 0.38 & 0.58 & 0.73 & 0.77 & 0.73 & 0.38 & 0.58 & 0.73 & 0.77 & 0.73 & \\
\hline & & i & 54 & 61 & 65 & 72 & 76 & 54 & 61 & 65 & 72 & 76 & \\
\hline & 5 & ii & 2 & 4 & 5 & 10 & 20 & 2 & 4 & 5 & 10 & 20 & 77 \\
\hline & 5 & iii & 22 & 16 & 12 & 5 & 1 & 22 & 16 & 12 & 5 & 1 & \\
\hline & & Efficiency & 0.39 & 0.53 & 0.62 & 0.74 & 0.71 & 0.39 & 0.53 & 0.62 & 0.74 & 0.71 & \\
\hline & & $\bar{i}$ & 22 & 29 & 37 & 37 & 37 & 21 & 26 & 28 & 32 & 34 & \\
\hline & & ii & 2 & 5 & 23 & 40 & 81 & 2 & 4 & 4 & 11 & 21 & 37 \\
\hline & 1 & iii & 15 & 8 & 0 & 0 & 0 & 16 & 11 & 9 & 5 & 3 & \\
\hline & & Efficiency & 0.14 & 0.43 & 0.38 & -0.08 & -1.19 & 0.08 & 0.30 & 0.41 & 0.43 & 0.27 & \\
\hline & & $\mathrm{i}$ & 18 & 23 & 24 & 25 & 25 & 19 & 20 & 23 & 24 & 25 & \\
\hline & 2 & ii & 0 & 2 & 7 & 24 & 64 & 0 & 2 & 2 & 5 & 8 & 25 \\
\hline & & iii & 7 & 2 & 1 & 0 & 0 & 6 & 5 & 2 & 1 & 0 & \\
\hline & & Efficiency & 0.44 & 0.76 & 0.64 & 0.04 & -1.56 & 0.52 & 0.52 & 0.76 & 0.72 & 0.68 & \\
\hline & & $\bar{i}$ & 27 & 38 & 46 & 48 & 48 & 25 & 32 & 38 & 44 & 47 & \\
\hline & 3 & ii & 0 & 2 & 11 & 27 & 61 & 0 & 1 & 3 & 3 & 10 & 48 \\
\hline 2 & 3 & iii & 21 & 10 & 2 & 0 & 0 & 23 & 16 & 10 & 4 & 1 & \\
\hline & & Efficiency & 0.13 & 0.54 & 0.69 & 0.44 & -0.27 & 0.04 & 0.31 & 0.52 & 0.77 & 0.75 & \\
\hline & & $\mathrm{i}$ & 32 & 45 & 54 & 58 & 60 & 35 & 40 & 47 & 56 & 58 & \\
\hline & 4 & ii & 4 & 8 & 16 & 41 & 82 & 1 & 1 & 4 & 6 & 11 & 61 \\
\hline & 4 & iii & 29 & 16 & 7 & 3 & 1 & 25 & 21 & 14 & 5 & 3 & \\
\hline & & Efficiency & -0.02 & 0.34 & 0.51 & 0.23 & -0.38 & 0.15 & 0.30 & 0.48 & 0.74 & 0.72 & \\
\hline & & $\overline{\mathrm{i}}$ & 48 & 63 & 72 & 73 & 73 & 45 & 52 & 60 & 68 & 73 & \\
\hline & 5 & ii & 2 & 6 & 25 & 63 & 118 & 2 & 3 & 4 & 10 & 23 & 73 \\
\hline & 5 & iii & 25 & 10 & 1 & 0 & 0 & 28 & 21 & 13 & 5 & 0 & \\
\hline & & Efficiency & 0.34 & 0.77 & 0.75 & 0.16 & -0.74 & 0.25 & 0.46 & 0.70 & 0.87 & 0.82 & \\
\hline & & i & 8 & 12 & 12 & 12 & 12 & 9 & 10 & 12 & 12 & 12 & \\
\hline & 1 & ii & 1 & 1 & 5 & 10 & 23 & 1 & 1 & 1 & 2 & 4 & 37 \\
\hline & 1 & iii & 4 & 0 & 0 & 0 & 0 & 3 & 2 & 0 & 0 & 0 & \\
\hline & & Efficiency & 0.25 & 0.92 & 0.58 & 0.17 & -0.92 & 0.42 & 0.58 & 0.92 & 0.83 & 0.67 & \\
\hline & & $\overline{\mathrm{i}}$ & 28 & 41 & 46 & 48 & 49 & 26 & 35 & 40 & 44 & 45 & \\
\hline & 2 & ii & 0 & 0 & 8 & 28 & 68 & 0 & 0 & 0 & 3 & 8 & 25 \\
\hline & 2 & iii & 21 & 8 & 3 & 1 & 0 & 23 & 14 & 9 & 5 & 4 & \\
\hline & & Efficiency & 0.14 & 0.67 & 0.71 & 0.39 & -0.39 & 0.06 & 0.43 & 0.63 & 0.73 & 0.67 & \\
\hline & & i & 11 & 15 & 23 & 23 & 23 & 11 & 14 & 16 & 21 & 23 & \\
\hline & 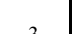 & ii & 0 & 3 & 11 & 31 & 69 & 0 & 1 & 2 & 4 & 9 & 48 \\
\hline 3 & 3 & $\mathrm{iii}$ & 12 & 8 & 0 & 0 & 0 & 12 & 9 & 7 & 2 & 0 & \\
\hline & & Efficiency & -0.04 & 0.17 & 0.52 & -0.35 & -2.00 & -0.04 & 0.17 & 0.30 & 0.65 & 0.61 & \\
\hline & & $\mathrm{i}$ & 9 & 14 & 18 & 18 & 18 & 8 & 11 & 13 & 17 & 18 & \\
\hline & 4 & ii & 0 & 0 & 6 & 29 & 57 & 0 & 0 & 0 & 3 & 6 & 61 \\
\hline & 4 & iii & 9 & 4 & 0 & 0 & 0 & 10 & 7 & 5 & 1 & 0 & \\
\hline & & Efficiency & 0.00 & 0.56 & 0.67 & -0.61 & -2.17 & -0.11 & 0.22 & 0.44 & 0.72 & 0.67 & \\
\hline & & $\bar{i}$ & 7 & 10 & 16 & 18 & 19 & 7 & 8 & 10 & 14 & 15 & \\
\hline & 5 & ii & 0 & 1 & 4 & 22 & 52 & 0 & 0 & 1 & 1 & 4 & 73 \\
\hline & 5 & iii & 12 & 9 & 3 & 1 & 0 & 12 & 11 & 9 & 5 & 4 & \\
\hline & & Efficiency & -0.26 & 0.00 & 0.47 & -0.26 & -1.74 & -0.26 & -0.16 & 0.00 & 0.42 & 0.37 & \\
\hline
\end{tabular}


Table5

\begin{tabular}{|c|c|c|c|c|c|c|c|c|c|c|c|c|c|}
\hline \multirow[t]{2}{*}{ Set } & \multirow[t]{2}{*}{ Hour } & \multirow[t]{2}{*}{ Check Type } & \multicolumn{5}{|c|}{$\begin{array}{c}\text { Strain gauge } D \text {, whipping stress derivative } \\
\left(\% \text { of } \sigma_{\text {allow }} / \mathrm{dt}\right)\end{array}$} & \multicolumn{5}{|c|}{$\begin{array}{c}\text { Strain gauge E, whipping stress derivative } \\
\left(\% \text { of } \sigma_{\text {allow }} / \mathrm{dt}\right)\end{array}$} & \multirow{2}{*}{$\begin{array}{c}\text { Visual } \\
\text { detection }\end{array}$} \\
\hline & & & $4.75 \%$ & $4.50 \%$ & $4.25 \%$ & $4.00 \%$ & $3.75 \%$ & $4.75 \%$ & $4.50 \%$ & $4.25 \%$ & $4.00 \%$ & $3.75 \%$ & \\
\hline \multirow{20}{*}{3} & \multirow{4}{*}{1} & $\mathrm{i}$ & 2 & 2 & 3 & 5 & 6 & 3 & 3 & 4 & 6 & 7 & \multirow{4}{*}{37} \\
\hline & & ii & 1 & 1 & 1 & 1 & 4 & 2 & 2 & 5 & 8 & 12 & \\
\hline & & & 10 & 10 & 9 & 7 & 6 & 9 & 9 & 8 & 6 & 5 & \\
\hline & & Efficiency & -0.75 & -0.75 & -0.58 & -0.25 & -0.33 & -0.67 & -0.67 & -0.75 & -0.67 & -0.83 & \\
\hline & \multirow{4}{*}{2} & i & 7 & 12 & 13 & 16 & 20 & 3 & 6 & 9 & 17 & 19 & \multirow{4}{*}{25} \\
\hline & & ii & 4 & 5 & 8 & 12 & 21 & 4 & 6 & 11 & 20 & 26 & \\
\hline & & & 32 & 27 & 26 & 23 & 19 & 36 & 33 & 30 & 22 & 20 & \\
\hline & & Efficiency & -0.74 & -0.51 & -0.54 & -0.49 & -0.51 & -0.95 & -0.85 & -0.82 & -0.64 & -0.69 & \\
\hline & \multirow{4}{*}{3} & i & 3 & 3 & 5 & 9 & 10 & 2 & 5 & 6 & 9 & 13 & \multirow{4}{*}{48} \\
\hline & & ii & 2 & 2 & 3 & 5 & 12 & 1 & 3 & 5 & 10 & 20 & \\
\hline & & iii & 20 & 20 & 18 & 14 & 13 & 21 & 18 & 17 & 14 & 10 & \\
\hline & & Efficiency & -0.83 & -0.83 & -0.70 & -0.43 & -0.65 & -0.87 & -0.70 & -0.70 & -0.65 & -0.74 & \\
\hline & \multirow{4}{*}{4} & i & 4 & 5 & 6 & 7 & 9 & 0 & 1 & 2 & 5 & 6 & \multirow{4}{*}{61} \\
\hline & & ii & 0 & 0 & 2 & 2 & 6 & 1 & 2 & 4 & 6 & 12 & \\
\hline & & iii & 14 & 13 & 12 & 11 & 9 & 18 & 17 & 16 & 13 & 12 & \\
\hline & & Efficiency & -0.56 & -0.44 & -0.44 & -0.33 & -0.33 & -1.06 & -1.00 & -1.00 & -0.78 & -1.00 & \\
\hline & \multirow{4}{*}{5} & $\mathrm{i}$ & 3 & 3 & 4 & 5 & 6 & 1 & 3 & 7 & 8 & 10 & \multirow{4}{*}{73} \\
\hline & & ii & 1 & 1 & 3 & 6 & 11 & 0 & 4 & 7 & 11 & 21 & \\
\hline & & iii & 16 & 16 & 15 & 14 & 13 & 18 & 16 & 11 & 11 & 9 & \\
\hline & & Efficiency & -0.74 & -0.74 & -0.74 & -0.79 & -0.95 & -0.89 & -0.89 & -0.58 & -0.74 & -1.05 & \\
\hline
\end{tabular}




\begin{tabular}{|c|c|c|c|c|c|c|c|c|c|c|}
\hline \multirow{2}{*}{$\Delta \boldsymbol{\sigma} / \boldsymbol{\sigma}_{\text {allow }}$} & \multicolumn{2}{|c|}{ Set 1, Hour 1 } & \multicolumn{2}{c|}{ Set 1, Hour 2 } & \multicolumn{2}{c|}{ Set 1, Hour 3 } & \multicolumn{2}{c|}{ Set 1, Hour 4 } & \multicolumn{2}{c|}{ Set 1, Hour 5 } \\
\cline { 2 - 10 } & $\begin{array}{c}\text { Wave } \\
\text { stress n }\end{array}$ & $\begin{array}{c}\text { Total } \\
\text { stress n }\end{array}$ & $\begin{array}{c}\text { Wave } \\
\text { stress n }\end{array}$ & $\begin{array}{c}\text { Total } \\
\text { stress n }\end{array}$ & $\begin{array}{c}\text { Wave } \\
\text { stress n }\end{array}$ & $\begin{array}{c}\text { Total } \\
\text { stress n }\end{array}$ & $\begin{array}{c}\text { Wave } \\
\text { stress n }\end{array}$ & $\begin{array}{c}\text { Total } \\
\text { stress n }\end{array}$ & $\begin{array}{c}\text { Wave } \\
\text { stress n }\end{array}$ & $\begin{array}{c}\text { Total } \\
\text { stress n }\end{array}$ \\
\hline 0.18 & 30 & 37 & 23.5 & 30.5 & 25.5 & 36.5 & 22 & 18.5 & 25 & 34.5 \\
0.23 & 6.5 & 15 & 8 & 12 & 7.5 & 9 & 4.5 & 13.5 & 7.5 & 8.5 \\
0.28 & 5 & 5.5 & 5.5 & 5.5 & 2.5 & 5.5 & 3 & 4 & 6 & 6.5 \\
0.32 & 1.5 & 2.5 & 1.5 & 4.5 & 1.5 & 3.5 & 2 & 3 & 2 & 4.5 \\
0.37 & 0 & 2 & 2 & 1 & 0 & 0 & 0 & 1 & 0 & 1.5 \\
0.41 & 0 & 0 & 0 & 1.5 & 0 & 0 & 0 & 0 & 0 & 1 \\
\hline SUM & 43 & 62 & 40.5 & 55 & 37 & 54.5 & 31.5 & 40 & 40.5 & 56.5 \\
\hline$D I F F$. & \multicolumn{2}{|c|}{19} & \multicolumn{2}{|c|}{14.5} & \multicolumn{2}{|c|}{17.5} & \multicolumn{2}{|c|}{8.5} & & 16 \\
\hline
\end{tabular}

\begin{tabular}{|c|c|c|c|c|c|c|c|c|c|c|}
\hline \multirow[b]{2}{*}{$\Delta \sigma / \sigma_{\text {allow }}$} & \multicolumn{2}{|c|}{ Set 2, Hour 1} & \multicolumn{2}{|c|}{ Set 2, Hour 2} & \multicolumn{2}{|c|}{ Set 2, Hour 3} & \multicolumn{2}{|c|}{ Set 2, Hour 4} & \multicolumn{2}{|c|}{ Set 2, Hour 5} \\
\hline & $\begin{array}{c}\text { Wave } \\
\text { stress n }\end{array}$ & $\begin{array}{c}\text { Total } \\
\text { stress n }\end{array}$ & $\begin{array}{c}\text { Wave } \\
\text { stress n }\end{array}$ & $\begin{array}{c}\text { Total } \\
\text { stress n }\end{array}$ & $\begin{array}{c}\text { Wave } \\
\text { stress n }\end{array}$ & $\begin{array}{c}\text { Total } \\
\text { stress n }\end{array}$ & $\begin{array}{c}\text { Wave } \\
\text { stress n }\end{array}$ & $\begin{array}{c}\text { Total } \\
\text { stress n }\end{array}$ & $\begin{array}{c}\text { Wave } \\
\text { stress n }\end{array}$ & $\begin{array}{c}\text { Total } \\
\text { stress n }\end{array}$ \\
\hline 0.18 & 20.5 & 31 & 17 & 21.5 & 19.5 & 27.5 & 27 & 36.5 & 35 & 39.5 \\
\hline 0.23 & 3.5 & 8.5 & 5.5 & 7.5 & 8 & 12 & 5.5 & 7.5 & 11.5 & 19 \\
\hline 0.28 & 1 & 1 & 2.5 & 3 & 1.5 & 3.5 & 2 & 3.5 & 2.5 & 6.5 \\
\hline 0.32 & 0.5 & 1 & 0 & 2 & 1 & 1 & 0 & 1 & 1 & 2 \\
\hline 0.37 & 1 & 1 & 0 & 0.5 & 0.5 & 1 & 2.5 & 2.5 & 0 & 1 \\
\hline 0.41 & 0 & 1 & 0 & 0 & 0 & 0.5 & 0 & 0 & 0 & 0 \\
\hline SUM & 26.5 & 43.5 & 25 & 34.5 & 30.5 & 45.5 & 37 & 51 & 50 & 68 \\
\hline DIFF. & \multicolumn{2}{|c|}{17} & \multicolumn{2}{|c|}{9.5} & \multicolumn{2}{|c|}{15} & \multicolumn{2}{|c|}{14} & \multicolumn{2}{|c|}{18} \\
\hline
\end{tabular}

\begin{tabular}{|c|c|c|c|c|c|c|c|c|c|c|}
\hline \multirow[b]{2}{*}{$\Delta \sigma / \sigma_{\text {allow }}$} & \multicolumn{2}{|c|}{ Set 3, Hour 1} & \multicolumn{2}{|c|}{ Set 3, Hour 2} & \multicolumn{2}{|c|}{ Set 3, Hour 3} & \multicolumn{2}{|c|}{ Set 3, Hour 4} & \multicolumn{2}{|c|}{ Set 3, Hour 5} \\
\hline & $\begin{array}{c}\text { Wave } \\
\text { stress n }\end{array}$ & $\begin{array}{c}\text { Total } \\
\text { stress n }\end{array}$ & $\begin{array}{c}\text { Wave } \\
\text { stress n }\end{array}$ & $\begin{array}{c}\text { Total } \\
\text { stress n }\end{array}$ & $\begin{array}{c}\text { Wave } \\
\text { stress n }\end{array}$ & $\begin{array}{c}\text { Total } \\
\text { stress n }\end{array}$ & $\begin{array}{l}\text { Wave } \\
\text { stress n }\end{array}$ & $\begin{array}{c}\text { Total } \\
\text { stress n }\end{array}$ & $\begin{array}{c}\text { Wave } \\
\text { stress n }\end{array}$ & $\begin{array}{c}\text { Total } \\
\text { stress n }\end{array}$ \\
\hline 0.18 & 6 & 9.5 & 18.5 & 28 & 12 & 13.5 & 6.5 & 12 & 7 & 11 \\
\hline 0.23 & 3.5 & 2 & 3.5 & 6.5 & 1 & 6.5 & 2.5 & 1.5 & 0.5 & 2.5 \\
\hline 0.28 & 0.5 & 2.5 & 1.5 & 2 & 0.5 & 1.5 & 0 & 1 & 0.5 & 1 \\
\hline 0.32 & 0 & 0 & 0 & 1 & 0 & 0 & 0 & 0.5 & 0 & 0 \\
\hline 0.37 & 0 & 0 & 0 & 0 & 0 & 0 & 0 & 0 & 0 & 0 \\
\hline 0.41 & 0 & 0 & 0 & 0 & 0 & 0 & 0 & 0 & 0 & 0 \\
\hline SUM & 10 & 14 & 23.5 & 37.5 & 13.5 & 21.5 & 9 & 15 & 8 & 14.5 \\
\hline DIFF. & \multicolumn{2}{|c|}{4} & \multicolumn{2}{|c|}{14} & \multicolumn{2}{|c|}{8} & \multicolumn{2}{|c|}{6} & \multicolumn{2}{|c|}{6.5} \\
\hline
\end{tabular}

